\title{
Judgement and supply chain dynamics
}

\section{(Journal of the Operational Research Society, in press)}

\author{
Aris A. Syntetos ${ }^{1 *}$, Nicholas C. Georgantzas ${ }^{2}$, John E. Boylan ${ }^{3}$, Brian C. Dangerfield ${ }^{1}$ \\ ${ }^{1}$ University of Salford, UK; ${ }^{2}$ Fordham University, USA, ${ }^{3}$ Buckinghamshire New University, UK
}

\begin{abstract}
Forecasting demand at the individual stock-keeping-unit (SKU) level often necessitates the use of statistical methods, such as exponential smoothing. In some organizations, however, statistical forecasts will be subject to judgemental adjustments by managers. Although a number of empirical and 'laboratory' studies have been performed in this area, no formal OR modelling has been conducted to offer insights into the impact such adjustments may have on supply chain performance and the potential development of mitigation mechanisms. This is because of the associated dynamic complexity and the situation-specific nature of the problem at hand. In conjunction with appropriate stock control rules, demand forecasts help decide how much to order. It is a common practice that replenishment orders may also be subject to judgemental intervention, adding further to the dynamic system complexity and interdependence. The system dynamics (SD) modelling method can help advance knowledge in this area, where mathematical modelling cannot accommodate the associated complexity. This study, which constitutes part of a UK government funded (EPSRC) project, uses SD models to evaluate the effects of forecasting and ordering adjustments for a wide set of scenarios involving: three different inventory policies; seven different (combinations of) points of intervention; and four different (combinations of) types of judgmental intervention (optimistic and pessimistic). The results enable insights to be gained into the performance of the entire supply chain. An agenda for further research concludes the paper.
\end{abstract}

Keywords: System Dynamics; Inventory Forecasting, Human Judgement; Bullwhip.

Electronic companion: Additional information pertinent to the modelling and results presented in this paper is available at: http://www.mams.salford.ac.uk/CORAS/Projects/SD/.

Acknowledgements: The research described in this paper has been funded by the Engineering and Physical Sciences Research Council (EPSRC, UK) grant no. EP/G070369/1 (a project entitled: Cognitive Mapping, System Dynamics and the Bullwhip Effect). More information on this project may be obtained at: http://www.mams.salford.ac.uk/CORAS/Projects/SD/.

\footnotetext{
* Corresponding author : $\quad$ Dr Aris A. Syntetos

Centre for OR and Applied Statistics, Salford Business School

University of Salford, Maxwell Building, Salford M5 4WT, UK

e-mail: a.syntetos@salford.ac.uk

Tel: $\quad+44(0) 1612955804$
} 


\section{Introduction}

Judgemental adjustments constitute one of the few practical ways for organisations to take account of internal and external performance drivers in their demand forecasts (Fildes et al, 2009). Experts may know that institutions will change, that events have a specific impact that is not included in the model being used, or that a variable difficult to measure is missing from the model. Such knowledge is often reflected by adjustments to the statistical or model-based forecasts produced by software solutions.

A number of empirical and 'laboratory' studies have been conducted to evaluate the effect of such adjustments on the forecasting task. A few attempts have also been made to model adjustments to offer some insights into their underlying properties (Fildes et al, 2009; Franses, 2007). However, no formal modelling has been conducted that could offer insight into the impact such adjustments might have on the entire supply chain performance and the potential development of mechanisms to mitigate any adverse effects. This is because of the associated dynamic complexity that precludes the development of closed-form mathematical models, unless rather simplifying (and thus not particularly realistic) assumptions are employed for such an exercise.

Moreover, while the effect of judgemental adjustments on forecast accuracy has received attention in the academic literature, its inventory implications have been largely ignored. A number of research projects have demonstrated that the efficiency and effectiveness of inventory systems do not relate directly to demand forecasting performance, as measured by standard forecasting accuracy measures. Syntetos et al (2009b, 2010) examined the 
stock control implications of judgementally adjusting statistical forecasts through the consideration of relevant accuracy-implication metrics (inventory and service level achieved). They found that the inventory performance could not be explained in terms of the forecast accuracy alone and that the inventory benefits were of a completely different order of magnitude to the forecast accuracy gains. Both results can be attributed, conceptually at least, to the interdependence between forecasting methods and stock control rules in inventory management systems (Syntetos and Boylan, 2008). However, presently, the dynamic effects of such interactions are not fully understood. In particular, the reasons why relatively small forecast accuracy changes may translate into significant inventory benefits requires more investigation. It is the contention of this paper that the system dynamics (SD) modeling method can play a crucial role in advancing knowledge in this area, where mathematical modeling cannot accommodate the associated dynamic complexity.

In an inventory setting, demand forecasts are used in conjunction with appropriate stock control rules in order to decide how much to order. Kolassa et al (2008) examined the inventory systems of three major German retail corporations and reported that replenishment orders may also be subject to judgemental intervention. (This may, or may not, occur in conjunction with judgementally adjusting sales forecasts.) Our study constitutes part of a UK government (EPSRC) project and all our industrial partnering organisations in this project rely, to a certain extent, on adjusting forecasts and/or replenishment orders. This is also true for a number of other companies we have 
examined. The effects of judgementally adjusting replenishment orders have never been studied before or explored in the academic literature.

Judgemental adjustments should have a considerable effect on supply chain performance and the creation of bullwhip-type phenomena through, for example, stock amplification as we move upstream in the supply chain. The purpose of our work is to study this effect in detail. Our investigation entails the application of SD models on a wide-range of scenarios, to evaluate the effects of forecasting and/or ordering adjustments on supply chain performance. A three-stage supply chain is considered (Retailer, Wholesaler (Home Office/Co-ordinating Unit) and Factory) and results are presented for three wellknown stock control policies: i) the linear Anchor and Adjust (AaA); ii) the re-order point $s$, order-up-to-level $S(s, S)$; and iii) the order-up-to-level $S(u t S)$. Other control parameters include the point of intervention (the stage at which the supply chain managers intervene to make the adjustments, including all possible combinations), and the nature of the adjustments (purely optimistic, purely pessimistic and mixed downward and upward optimistic and pessimistic). The performance metric we employ is the factory stock amplification ratio (Sterman, 2000, p. 673), which relates the maximum change in stocks at the factory level to the maximum change in forecasts or orders, as a consequence of judgemental adjustment. The results enable insight to be gained into the effects of judgemental interventions on bullwhip amplification in the supply chain.

The remainder of our paper is structured as follows: in the next Section the research background is presented, followed in Section 3 by the experimental structure employed 
for the purposes of our research. Details related to SD modelling are presented in Section 4. Section 5 contains the results of our investigation and their analysis and interpretation. The paper concludes with an agenda for further research in Section 6 .

\section{Research background}

In this section the literature related to our research is reviewed under three main subsections. First, we discuss studies that have considered the effects of judgemental interventions in supply chain management. Second, we review contributions in the area of the bullwhip effect; its contributory factors are synthesized in a diagram that illustrates the potential effects of judgemental interventions. Third, we consider a number of SD projects that focus on supply chain modelling and management.

\subsection{Judgemental interventions in supply chain management}

Franses (2007) investigated judgemental adjustments to model-based forecasts and explored whether they contributed to forecasting accuracy, i.e. is there any value being added? He also examined whether the contribution of the model forecast and that of the expert added value (as opposed to expert forecast) are of equal importance, i.e. does the 50\% model - 50\% manager rule (advocated by Blattberg and Hoch, 1990) hold?

In the above study, the null hypothesis that the root mean squared error prediction (RMSPE) of the expert is equal to that of the model (against the alternative that the expert is better) was tested based on recommendations proposed by Clark and McCracken, (2001, 2005 - one-sided tests). The empirical dataset consisted of monthly observations 
(demand realizations, model and expert forecasts) for a wide range of pharmaceutical products belonging to different categories and sold across many countries.

The main conclusions are that the expert's added value frequently matters and when it matters it also frequently occurs on a 50-50 basis, but the experts put too much emphasis on their own added contribution. The implications of this research project are viewed as very important: i) the way the statistical model works should be better communicated to the experts; ii) experts should start documenting what they effectively do when they adjust model based forecasts; iii) the experts should become aware that they may be putting too much weight on their expertise. When expert judgement is useful, there is no problem, but when it is not, forecasts can become dramatically bad.

A further attempt to investigate the properties of expert adjustments on model-based SKU level forecasts was made by Franses and Legerstee (2009). They analysed a database containing one-step-ahead model-based forecasts adjusted by many experts located in 37 countries, who make forecasts for pharmaceutical products within seven distinct categories. Their results were consistent with earlier findings that the experts make frequent adjustments (managers were found to adjust model-based forecasts in $90 \%$ of the cases) and that these tend to be upward. In addition, they found that expert adjustment itself is largely predictable, where the weight of a forecaster's own earlier adjustment is about three times as large as the weight of past model-based forecast errors. Finally, they showed that expert adjustment is not independent of the model-based forecasts. They 
argued that this interaction should be taken into account in any evaluation of the effect of the contribution of expert adjustment to the overall forecast quality.

Fildes et al (2009) collected data from more than 60,000 forecasts from four supply chain companies. In three of the companies, on average, judgemental adjustments were found to increase accuracy. However, detailed analysis revealed that while the relatively larger adjustments tended to lead to greater average improvements in accuracy, the smaller adjustments often damaged accuracy. In addition, positive adjustments, which involved adjusting the forecast upwards, were much less likely to improve accuracy than negative adjustments. They were also made in the wrong direction more frequently, suggesting a general bias towards optimism. Models were then developed to eradicate such biases.

Small adjustments have been found not to be very effective. This is confirmed by analysis of both intermittent and faster-moving demand data by Syntetos et al (2009b) and Fildes et al (2009) respectively. It seems that in this case the experts merely add 'noise' to the forecasts resulting in higher errors however the errors are measured. Consequently, it may be useful modelling the adjustments (under those conditions) for the purpose of further developing our understanding of their implications. We note that the analysis under concern reflects the unfavourable setting where adjustments do not perform well, i.e. they do not convey an important piece of information that would be lost otherwise. 
Eroglu (2006) explored the variables that affect a forecaster's performance when making judgmental adjustments to statistical forecasts (see also Eroglu and Croxton, 2010). He also looked at the conditions under which judgmental adjustments were beneficial or detrimental to forecasting performance. Eroglu (op. cit.) examined two other important issues both of which have received insufficient attention in this context in the academic literature: learning and biases.

The data set used in the study came from the forecasting records of a company that judgmentally adjusted statistical forecasts to improve the forecast accuracy. The original (statistical) forecast, the adjusted forecast and the actual sales in the corresponding time period were retrieved from the research company's data warehouse. Forecasting performance (accuracy improvement, learning and biases) was calculated using these data. The study covered a period of 12 months from the beginning of June 2004 to end of May 2005. Most interestingly, the data set was augmented with independent variables that were measured with a survey instrument, administered in 390 company stores located in several Midwestern and southeastern states in the USA. Pertinent constructs included personality, motivational and situational variables. The survey responses were matched with corresponding judgmental adjustments made by the respondent. The main conclusions can be summarized as follows: i) the analysis of the data provided evidence for accuracy improvement; ii) the data analysis provided no evidence of learning; iii) in addition to accuracy improvement, data analysis detected evidence of biases (optimism bias and overreaction bias). 


\subsection{Factors influencing the bullwhip effect}

The Bullwhip Effect is a term promoted by Lee et al (1997a) but was observed and modelled decades earlier by Forrester (1958). It occurs whenever demand becomes more variable as it proceeds through the supply chain, away from the consumer and towards the supplier. Recent research on the Bullwhip Effect (e.g. Lee et al, 2000; Zhang, 2004) has tended to focus on mathematical modelling and has treated one cause of bullwhip independently of the others. The potential to use SD to understand the interactions between causes of the Bullwhip Effect is partly addressed by the research reported in this paper.

Lee et al (2000) discussed four causes of the Bullwhip Effect, namely: demand signal processing, rationing/shortage gaming, order batching and price fluctuations.

Demand signal processing refers to the magnification in variance that occurs through the interaction between forecasting procedures and inventory rules at each stage of the supply chain (see also Chen et al, 2000a, b; Wong et al, 2007; for a review of studies in this area please refer to Syntetos et al, 2009a).

Lee et al (1997b) argued that rationing and shortage gaming is a major cause of the Bullwhip Effect and occurs in situations where the demand exceeds the production capacity. In these situations, the manufacturer may ration or allocate supplies to the retailers. On recognising the rationing criteria, the retailer may place orders exceeding the required quantity, to secure a greater share of the supplies from the manufacturer. This 
gives the manufacturer a false impression of the true demand and they in turn place large orders on their suppliers. This particular cause of the bullwhip effect has also been discussed, amongst others, by Cachon and Lariviere (1999), Cheung and Zhang (1999) and Paik and Bagchi (2007).

A common practice in industry is not to place orders on the upstream link as soon as demand arises. Instead, the individual demands are batched or accumulated before placing the orders (order batching) and thus, instead of frequent orders, weekly, biweekly or monthly orders are placed. This is done for various reasons including economies of scale and distribution efficiencies, or similar factors (see, for example, Potter and Disney, 2006; Pujawan, 2004).

Price fluctuations refer to the practice of offering products at reduced prices in order to stimulate demand (e.g. Gavirneri, 2006; Reiner and Fichtinger, 2009). For price-elastic products, when the price of an item changes, the customer demand will also change. Customers buy in bulk quantities when the price of the product is low. Then, customers stop buying when the price returns to normal, until they have exhausted their inventory. Thus, the actual customer sales do not match the true demand for the product when there are price variations. This results in the Bullwhip Effect, as the variance of the order quantities amplifies upstream because of the temporary price reductions.

There have been numerous papers investigating these causes individually, but little attention has been paid to their interaction. Such interactions may be adequately captured 
with the help of the SD modeling method. A critical element in any bullwhip effect model is the variance of upstream orders. Figure 1 shows a basic map of the most important factors that influence the bullwhip effect.

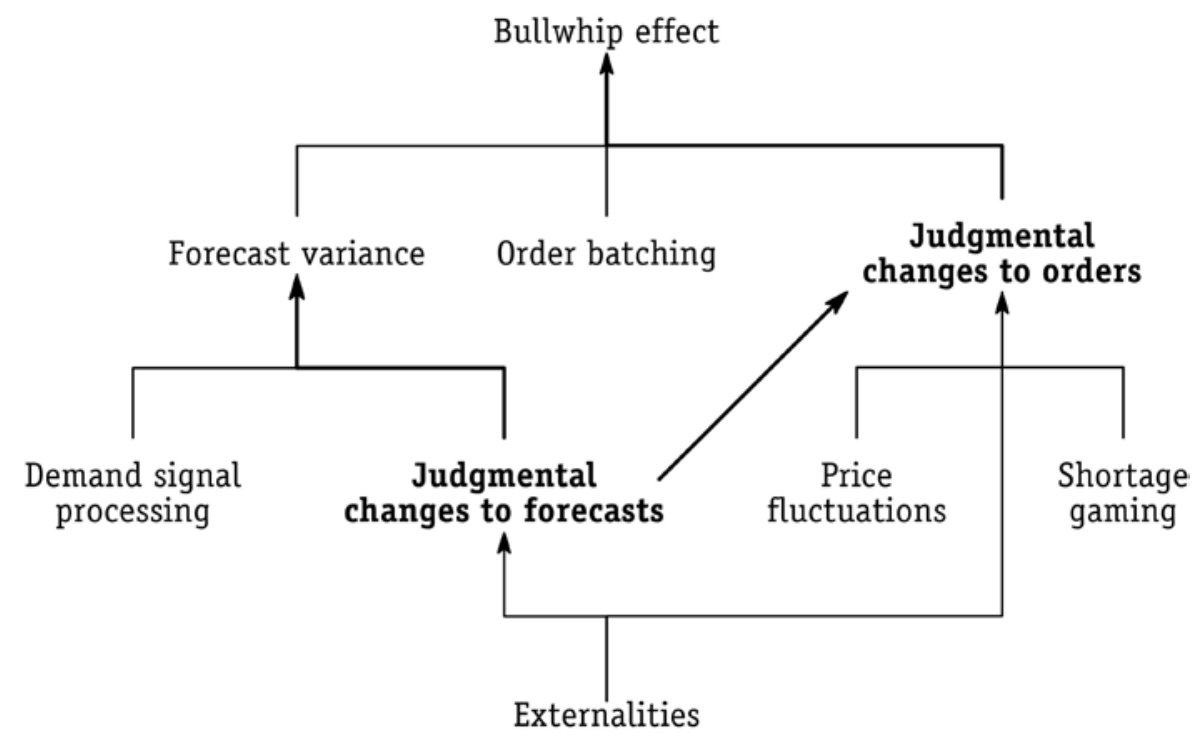

Figure 1. Factors impinging on the bullwhip effect

This example of a generic or archetypal causal map (Figure 1) highlights two behavioural factors: i) judgemental changes to forecasts and ii) judgemental changes to orders. The second may be distinct from the first, as it is not necessarily based on any expectation of a changed demand pattern, but rather on a subjective reaction to external stimuli (e.g. change in price, shortage of supply). However, the former may indeed affect the latter if a single person, for example, performs both adjustments. Similarly, in the context of a small organization, the judgemental adjustments of the orders may reflect a certain reaction mechanism on the part of the stock controller to known adjustment behaviours on the forecasting side. The distinction between forecasting and ordering adjustments has been neglected in much of the academic forecasting literature, but is very important in practice (Kolassa et al, 2008). 


\subsection{System Dynamics modelling of supply chains}

The initial exposition of this application topic in SD was made by Forrester $(1958,1961)$. He considered a three-stage supply chain, demonstrating the now well-known amplification of orders as they are transmitted upstream. He explicitly considered the inventory policy as a cause of this. Orders were determined through a policy which considered: (desired - actual inventory) + (desired - actual orders in the pipeline) + (actual - normal unfilled orders). To preserve the dimensional consistency, each of these terms has to be divided by an adjustment time which Forrester emphasised was a critical explanatory factor in the determination of the overall system behaviour. The 'desired' values were obtained by smoothing an actual demand flow and then multiplying by a number of units of coverage.

Barlas and Ozevin (2004) investigated two different yet related research questions about stock management in feedback environments. The first purpose was to analyse the effects of selected experimental factors on the performances of subjects (players) in a stock management simulation game. In the light of these results, the second objective was to evaluate the adequacy of standard decision rules typically used in dynamic stock management models and to seek improved formulations. In the first part, gaming experiments were designed to test the effects of three factors on decision-making behaviour: different patterns of customer demand, minimum possible order decision (review) interval and, finally, the type of receiving delay. These factors were analysed with regards to their effect on 10 different measures of behaviour (such as max-min range of orders, inventory amplitudes, periods of oscillations and backlog durations). 
In the second phase of research, the performances of subjects were compared against some selected ordering heuristics (formulations). These included the linear 'anchoring and adjustment rule' (commonly used in SD studies), several alternative non-linear rules, and some standard discrete inventory control rules common in the inventory management literature. The non-linear and/or discrete rules, compared with the linear stock adjustment rule, were found to be more representative of the subjects' ordering behaviour in many cases, in the sense that these rules could generate non-linear and/or discrete ordering behaviours. Another important finding was that the well-documented oscillatory dynamic behaviour of the inventory is a quite general result, not just an artefact of the linear anchor and adjust rule.

Saeed (2009) examined the use of trend forecasting in driving ordering policies in supply chains by comparing it with derivative control in classical control theory. He found that although both processes involve the use of trend to determine policies for achieving reliable performance, the former often worsens instability while the latter can improve stability with certainty. The similarities and differences between the two processes were discussed and a framework was suggested for improving the efficacy of trend forecasting in ordering policies.

Yasarcan and Barlas (2005) proposed a generalized SD stock control formulation for stock management problems involving information delays and delays implicit in controlling a primary stock indirectly via a secondary stock. It is well-accepted that the behaviour of a standard SD stock management structure can be highly oscillatory if the 
stock control formulation (typically the linear anchoring and adjustment rule) does not take into account the supply line (material) delays. However, such delays do not constitute the only type of delay in stock management problems; there are other types such as information delays in decision processing, delays caused in trying to control a stock indirectly via a secondary stock and combinations of these. Yasarcan and Barlas (op. cit.) investigated the implications of ignoring such composite and indirect delays in the stock control formulation. They showed that the consequences of ignoring information delay in the decision stream or ignoring the delay implicit in secondary stock control are both equivalent to ignoring the supply line delay in the standard case: large, possibly unstable, oscillations. Subsequently, they proposed a generalised stock control heuristic that does take into account these more advanced types of delays and showed that the result is stabilised dynamic behaviour. In this research, they introduced the notion of a 'virtual supply line' (VSL), a conceptual generalisation of the standard notion of supply line delay to structures involving information delays and 'secondary stock controlinduced-delays'. They implemented their generalised decision heuristic on a complex example involving all three types of delays, demonstrating the usefulness of the proposed formulation whilst illuminating some implementation issues.

Croson and Donohue (2005) examined whether giving supply chain partners access to downstream inventory information is more effective at reducing bullwhip behaviour, and its associated costs, than similar access to upstream inventory information. They used a controlled version of the Beer Distribution Game as the setting for their experiment, and varied the amount and location of inventory information shared across treatments. They 
first independently tested whether sharing upstream or downstream inventory information helps reduce bullwhip behaviour, and found that only downstream information sharing leads to significantly lower order oscillations throughout the supply chain. Subsequently, they compared the reduction in order oscillations experienced by supply chain level and found that upstream supply chain members benefit the most from downstream information sharing. A very important observation of this study is that it is not the information per se but the interaction between the information and the decision setting that has the potential to improve performance in dynamic tasks.

For some very interesting discussions on the role of system dynamics in supply chain management and its usefulness for performance measurement in such a context, the reader is referred to Akkermans and Dellaert (2005), Kleijnen and Smits (2003), and Otto and Kotzab (2003).

The brief literature review on SD in supply chains presented in this sub-section shows that only a small part of the generic map shown in Figure 1 has been addressed using a system dynamics approach. In this paper, we go further and incorporate judgemental changes to orders and to forecasts into an SD model of a three-stage supply chain. We will not examine shortage gaming or price fluctuations. Order batching will not be analysed directly, although batching effects will be observed in one of the inventory management rules. It is hoped that the work reported here will provide a springboard for more comprehensive SD models of bullwhip effects. 


\section{Experimental structure}

Excluding the final user stage, a three-stage supply chain has been considered for the purposes of this investigation (Figure 2). It consists of a factory $(F)$ or supplier stage, a home office $(H)$ stage, where $H$ takes the role of wholesaler, and a client $(C)$ stage that acts as a retailer, serving the final end consumers. Each stage contains three sub-stages (called Work-In-Progress, WIP) which may represent such processes as booking in and inspection.

Our SD models show the middle stage $H$ (wholesaler) as the home office or HeadQuarters of a vertically integrated supply chain or, correspondingly, the 'co-ordinating' unit (in terms of material and information flows) of any supply chain that consists of separate business entities. Consequently, the retailer may be viewed as the wholesaler's client $(C)$ that in turn serves customers in the final user stage.

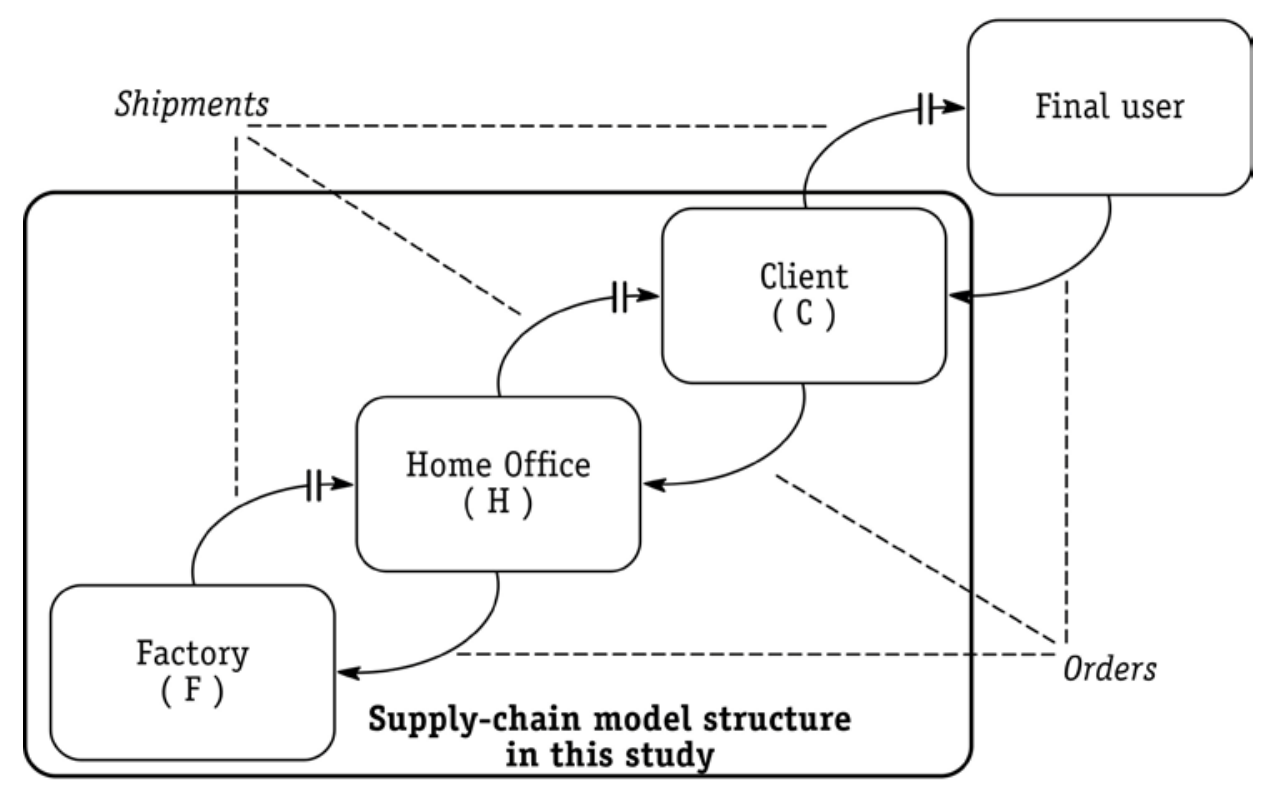

Figure 2. Supply-chain model structure in this study 
The demand experienced at the client (retailing) stage is assumed to be deterministic and constant at 100 items per week. The time unit chosen for all experimental results equals 1 (one) week. Other time buckets could have been chosen but weekly periods constitute a realistic reflection of various industries, stages in a given supply chain and inventory control systems.

With regards to the demand, we considered the possibility of introducing some random variations to the underlying pattern, but that would necessitate conducting multiple runs (30 at least) for each experimental scenario for the purpose of averaging the results, leading to a totally unrealistic size of the simulation output. Likewise, a deterministic sine wave could have been introduced. However, the judgemental adjustment effects would not then be distinguishable from the deterministic sine wave effects on the observed bullwhip. On the other hand, the flat deterministic demand pattern renders the application of any forecasting method, such as single exponential smoothing (SES), redundant and thus forecasting adjustments cannot be evaluated. To overcome this problem, demand is indeed assumed to be forecasted using SES, but the forecast adjustment intervention occurs on the input of the SES procedure rather than on its output, i.e., actual demand data are adjusted in lieu of the forecast output. We return to this issue later in this section.

Results have been generated for three stock control policies: i) the linear Anchor and Adjust (AaA); ii) the re-order point $s$, order-up-to-level $S(s, S)$; and iii) the order-up-tolevel $S$ (utS). Details governing the implementation of these three stock control policies follow in the next section. We assume that unfilled demand is backlogged, i.e no lost 
sales occur. All stages in the supply chain are assumed to employ the same stock control policy. We recognize that this is a rather restrictive assumption, but computational considerations dictate that we implement it in our SD supply-chain models. In addition, such a formulation would indeed reflect reality for a vertically integrated supply chain (or a supply chain connected through an ERP-type solution that dictates the employment of the same stock control policy through its functionality; in the case of SAP this would be the re-order point $s$, order-up-to-level $S$ policy). The lead time has been set to three time periods (weeks). This is a convenient assumption based on the real-life organizations we have worked with. Lastly, the SES smoothing constant $(\alpha)$ has been set equal to 0.2 , again something that conforms to generally accepted practices among forecasting practitioners.

The point(s) of intervention is also introduced as a control parameter in our modelling exercise. There are three stages in the system where adjustments can take place (Retailer, Wholesaler and Factory). We explore all possible single interventions (in only one of the three stages), dual interventions (in any two of the three stages) and finally a triple intervention (adjustments take place in every stage of the supply chain). This is in conjunction with the scenarios of: i) adjusting only the forecasts; ii) adjusting only the orders; and iii) adjusting both forecast and orders.

The type of adjustment is the last control parameter. Each simulation runs for 100 periods and adjustments are introduced periodically (in periods 8, 24 and 40) with a magnitude of 25\%. Fildes et al (2009) analysed more than 60,000 forecasts (along with their 
adjustments) from four supply chain companies. The median adjustments reported in this study, across the four datasets, in terms of their magnitude in relation to the forecasts, varied between 13\% and 33\% (depending also on their direction). Subsets of these datasets were also analysed by Syntetos et al (2009b, 2010). Both studies indicate that $25 \%$ constitutes a reasonable descriptive summarisation of the relative magnitude of the adjustments. Finally, the selection of this control parameter value has been also confirmed as a realistic one by the organisations partnering with us in this project. In one case (Electronics Manufacturer) it was disclosed that when human intervention is exercised on the size of the replenishment orders, the relative magnitude of the adjustments is always (as a rule of thumb) 25\%, regardless of the direction of the adjustment (plus or minus).

The optimism bias discussed in the previous section is reflected by consistent positive (upwards) adjustments introduced in our experiment. Inconsistent behaviour on the part of the managers with no sound justification as to why they are adjusting is reflected by a structure of alternate positive and negative adjustments. For completeness, consistent negative adjustments are considered as well. In all cases, the adjustments are unwarranted, as there is no change in the underlying demand pattern, allowing an assessment of the effect of un-necessary forecast adjustments on the supply chain.

Returning to the mechanism employed for forecast adjustment purposes, a realistic representation of this intervention would be to adjust the SES forecast by $25 \%$. Instead, we adjust the demand input to the SES forecast by $25 \%$. Although this may seem 
unnatural, there is little difference, for simulation purposes, between adjusting forecasts in the proposed way and intervening in a manner compatible with real world practices.

As discussed above, the SD models run for 100 periods and the interventions are introduced periodically in periods 8, 24 and 40. The different adjustment mechanisms introduce pulses, at the designated intervention points to the actual demand, with no change to the forecast. Subsequently, the actual demand remains unchanged (with no pulse), and the forecast increases upwards as a pulse, and then declines exponentially. This closely resembles the behaviour of a judgementally adjusted forecast which subsequently declines to adjust to the true level of demand. Most importantly, in this research we are concerned with the effects of such interventions on stock amplification. Consider the first intervention point as an example: Figure 3 shows a typical response of the SES procedure (under the $A a A$ stock policy) to the judgemental adjustment introduced in period (week) 8 along with the response of the stock held at the factory. The maximum amplification at the factory occurs on week 15 which is time distanced enough to justify that had we adjusted the SES forecast output itself, the difference would have been imperceptible. 


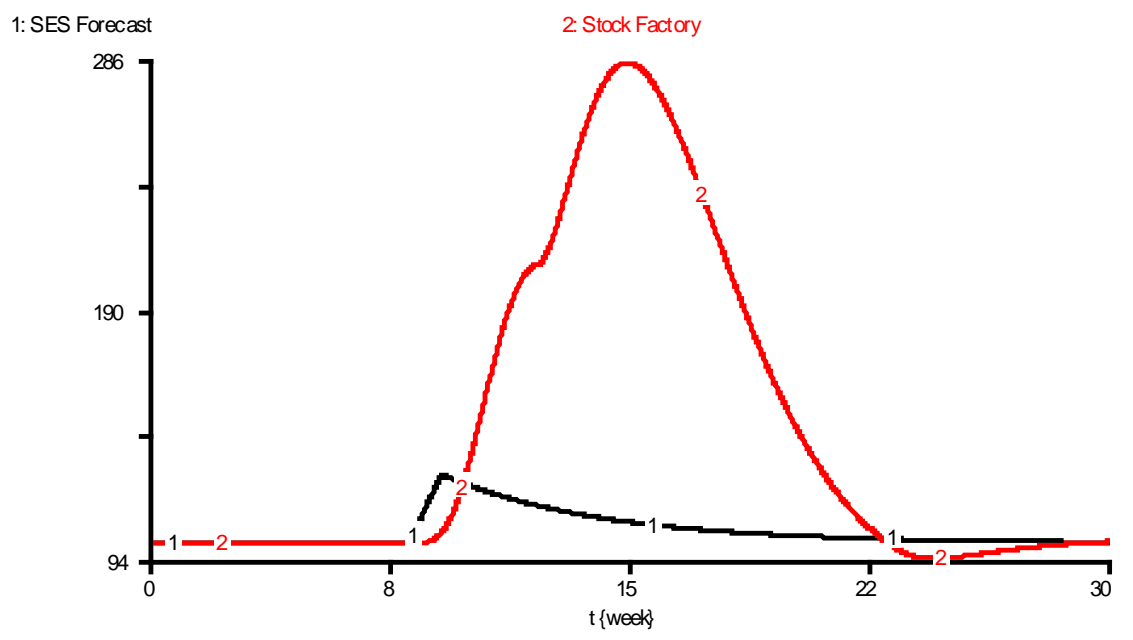

Figure 3. SES and factory stock response to adjustments

In addition, the adjustment mechanism used for the purposes of this research introduces pulses that are always of lower magnitude that than those resulting from adjusting the forecasts directly, because the change in actual demand is immediately smoothed. Thus, we are probably conservative with regards to the potential consequences we simulate for the whole supply chain. Finally, had the adjustment been of a lower percentage (say 5\%), the difference between the adjustment mechanisms would have been minor even in the intervention points. With regards to the replenishment orders, these are directly adjusted (by 25\%) upon their generation by any of the policies considered and in any of the SC stages.

Taking into account all these concerns, our final experimental design enables us to explore various combinations of forecast and order adjustments in terms of their plus or minus direction, thereby accounting for multiple scenarios of optimistic and pessimistic adjustments. It is likely, in large organisations, that the number of process stages between the forecast intervention point and the order intervention point is greater than in a small 
firm. Thus, the current structure allows simulating varying combinations of forecast and order adjustments, i.e., in terms of individuals' optimism and pessimism.

The experimental conditions considered for the purposes of our investigation are summarised in the Table 1. Owing to the very high number of experimental conditions, the gradual effect of adjusting forecasts and orders will only be reported for the Factory stock, as this is typically the stage exhibiting the greatest amplification in the whole supply chain. Also, due to the considerable amount of the output of our investigation it is natural that only some results may be presented here. However, an electronic companion has been introduced to our paper that may be accessed at: http://www.mams.salford.ac.uk/CORAS/Projects/SD/. This contains a more comprehensive selection of simulation outputs. The entire exercise has been performed using the $i T h i n k{ }^{\circledR}$ Software (Richmond et al, 2009). 


\begin{tabular}{|c|c|c|}
\hline Control parameter & Experimental scenarios & $\#$ \\
\hline Demand pattern & Deterministic, Constant & 1 \\
\hline Forecasting & Single Exponential Smoothing (SES) & 1 \\
\hline Inventory policies & $\begin{array}{c}\text { Anchor and Adjust }(A a A) \\
(s, S) \\
\text { up to } S(u t S) \\
\end{array}$ & 3 \\
\hline Intervention & $\begin{array}{c}\text { Adjust forecasts } \\
\text { Adjust orders } \\
\text { Adjust forecasts and orders }\end{array}$ & 3 \\
\hline Points of intervention & $\begin{array}{c}\text { Stage 1: client }(C) \\
\text { Stage 2: home }(H) \text { office } \\
\text { Stage 3: factory }(F) \\
\text { Stages } 1 \text { and 2: } C \text { and } H \\
\text { Stages } 1 \text { and 3: } C \text { and } F \\
\text { Stages } 2 \text { and 3: } H \text { and } F \\
\text { Stages 1, } 2 \text { and 3: } C, H \text { and } F\end{array}$ & 7 \\
\hline Optimism $(O)$ and pessimism $(P)$ & $\begin{array}{c}\text { Persistent pessimism: } P \cdot P \cdot P \\
\text { Persistent optimism: } O \cdot O \cdot O \\
\text { Mixed: } P \cdot O \cdot P \\
\text { Mixed: } O \cdot P \cdot O\end{array}$ & 4 \\
\hline
\end{tabular}

Table 1. Control parameters and experimental scenarios

\section{Model description}

The subsystem diagram of Figure 2 shows a typical supply-chain (SC), with the SD model structures in this article dynamically interconnected through material flows (i.e. shipments) and bundled information connectors (i.e. orders). Even small SD modelling examples, such as the one in Figure 2, show the interdependencies among variables connected through multiple feedback loops, which typically contain time lags and delays.

In order to show the different causal structure behind each stock policy used in this study, this section presents only the middle, home office $(H)$ stage (Figure 2 ), model sectors under each stock policy. In all three cases, the causal structure behind the client $(C$, 
Sector 1: not shown) and factory (F, Sector 3: not shown) supply-chain stages is almost identical to the one of the home office $(H)$ stage (Sectors 2a, 2b and 2c, Figure 4). The only difference is in the factory $(F)$ stage, which has to account for its own backlog only, thereby excluding a prior-stage backlog, simply because, under each stock control policy considered, the factory stage is assumed to be the very beginning of the entire chain.

Figure 4 shows the stock and flow diagram of the home $(H)$ supply-chain model sectors, under the anchor and adjust $(A a A)$ stock policy. There is a one-to-one correspondence between the model diagram on Figure 4 and its equations (Table A1, Appendix A). Building the model entailed first drawing the model structure and then specifying simple algebraic equations and parameter values. The iThink ${ }^{\circledR}$ Software enforces consistency between diagrams and equations, while its built-in functions help quantify parameters and variables pertinent to the causal structure of each stock control policy. As discussed in the previous section, we assume that all stages use the same stock policy consistently within their supply chain.

In the SD modelling method, rectangles represent stocks or level variables that can accumulate, such as the Work-In-Progress (WIP) A Home and Stock Home stocks (top of Figure 4 and Equations 1 and 2, Table A1). Emanating from cloud-like sources and ebbing into cloud-like sinks, the double-line pipe-and-valve-like icons that fill and deplete the stocks represent flows or rate variables that cause the stocks to change. The to stock home flow (Equation 7), for example, at once feeds the Stock Home stock and also depletes the WIP C Home stock, modulated by the WIP C Home level (Equation 4) and 
the lead time home (Equation 15). Single-line arrows represent information connectors, while circular or plain text icons depict auxiliary converters where behavioural relations, constants or decision points convert information into decisions. The coverage home auxiliary converter, for example, depends on both the lead time home converter and the Est D (estimated demand) Home stock (Equation 23).

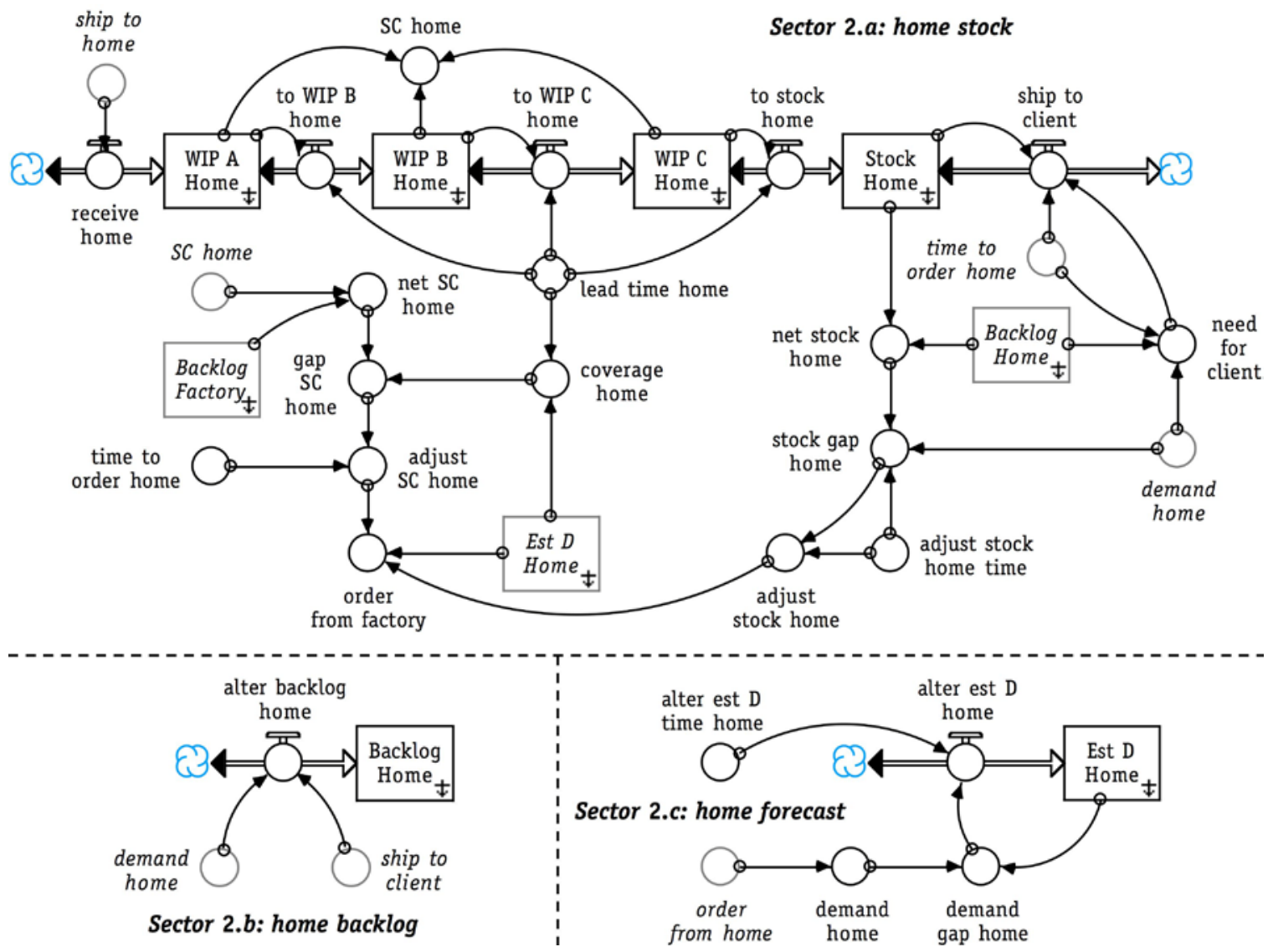

Figure 4. Stock and flow diagram of the home $(H)$ supply-chain model sectors, AaA

Supply chains always entail a stock and flow structure like the one on the top panel of Figure 4 for the acquisition, storage and conversion of inputs into outputs, and decision rules (middle of Figure 4) governing the flows. 
The causal structure of auxiliary variables and parameters in the middle of Figure 4 shows the decision rules pertinent to the $A a A$ stock control policy. This set of rules first 'anchors' the order from factory decision (Equation 19) on the adjust stock home converter (Equation 11) and then adjusts according to the adjust SC home (Equation 10). The order decision also takes into account the Est D Home stock (Equation 23), which essentially is the output of a SES forecasting procedure with $\alpha=0.2$ (Equations 26, 27 and 28).

Figure 5 shows the stock and flow diagram and Table A2 (Appendix A) the corresponding equations of the home $(H)$ supply-chain model sectors, under the $(s, S)$ stock control policy. Both the stock and flow structure on the top panel of Figure 5 and the corresponding equations in Table A2 are identical with the AaA stock policy model (Figure 4). So are the causal structure and corresponding equations of the home backlog and home forecast sectors on Figure 5 and Table A2. The only difference between the two models lies in the middle of Figure 5, showing the $(s, S)$ decision rules governing the stocks and flows of the supply chain on the top panel of Figure 5.

The middle right of Figure 5 now shows the stock position home converter (Equation. 39), which takes into account the Stock Home level, plus the SC home and its supplier's Backlog Factory, but it must subtract its own Backlog Home level of orders already placed but not yet received by its downstream client $(C)$ stage. The middle left of Figure 5 shows the variables and auxiliary constants that drive the $(s, S)$ based order from factory decision converter (Equation 33). In addition to the stock position home, the decision also 
depends on the (re-order point) s home converter (Equation. 36) as well the order up to $S$ home converter (Equation 35).

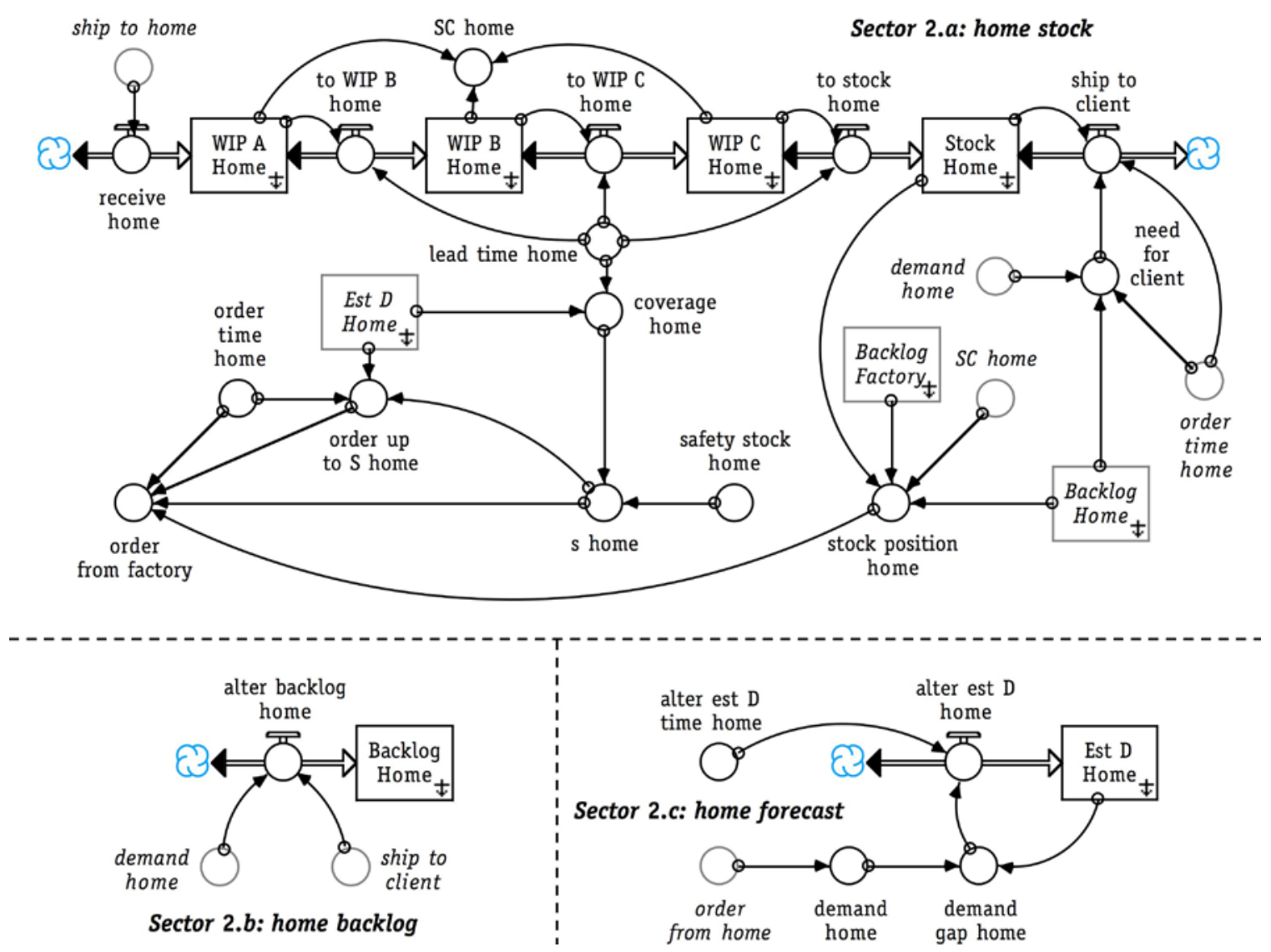

Figure 5. Stock and flow diagram of the home $(H)$ supply-chain model sectors, $(s, S)$

As the middle left of Figure 5 shows, the Est D Home SES forecast output and the order from factory decision point are closely positioned. The large safety stock home (Equation 37) guards against large backlogs and renders the $(s, S)$ model robust to large bullwhip effects. Also, it helps to easily initialize the model at steady state, a condition crucial if the computed simulation results are to make sense. Unless a SD model is initialized at 
steady state, then one might simply observe artefact dynamics attributable to initial transient conditions.

Figure 6 shows the stock and flow diagram and Table A3 (Appendix A) the corresponding equations of the home $(H)$ supply-chain model sectors, under the order up to S (utS) stock policy. Both the stock and flow structure on the top panel of Figure 6 and the corresponding equations in Table A3 are again identical with the $A a A$ stock policy model (Figure 4). So are the causal structure and related equations of the home backlog and home forecast sectors on Figure 6 and Table A3. Once more, the only difference between the two models lies in the middle of Figure 6, where the utS decision rules govern the stocks and flows of the supply chain on the top panel of Figure 6.

As under the $(s, S)$ policy, in the supply-chain rules on the middle of Figure 6, the stock position home converter (Equation 47, Table A3) takes into account the Stock Home level, plus the SC home and its supplier's Backlog Factory, but it must once more subtract its own Backlog Home level of orders already placed but not yet received by its client $(C)$ downstream. The middle of Figure 6 shows the variables and auxiliary constants that drive the utS -based order from factory decision converter (Equation 44). In addition to the stock position home, the ordering decision also depends on the order up to $S$ home converter (Equation 45) as well as the time to order home auxiliary constant (Equation 48). 

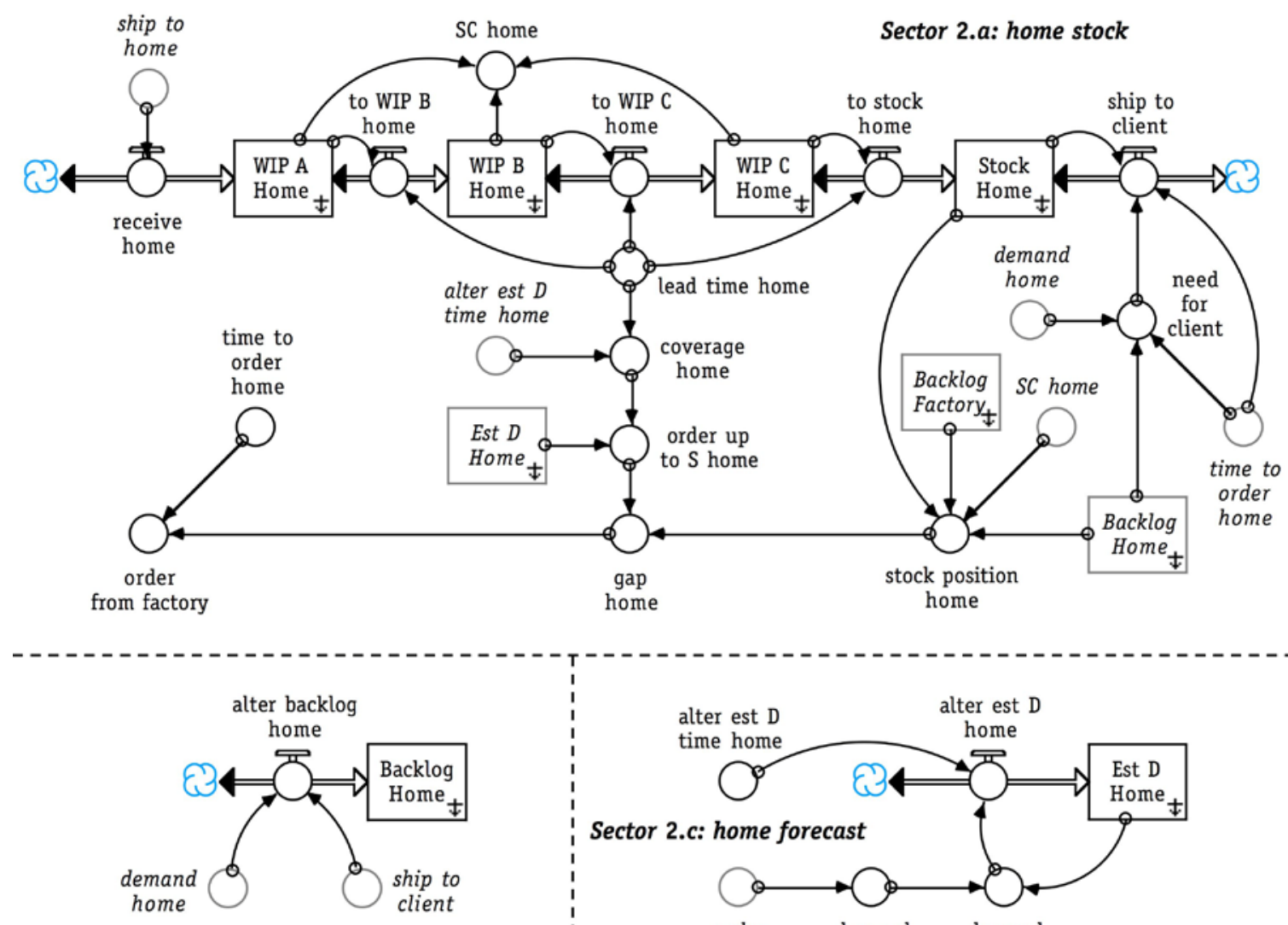

Sector 2.b: home backlog

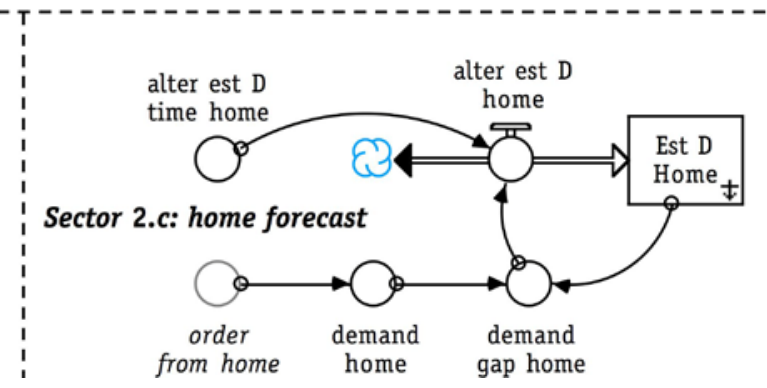

Figure 6. Stock and flow diagram of the home $(H)$ supply-chain model sectors, $u t S$

An important difference between the $u t S$ and the other two stock control policies used in this study has to do with the unit specification of the coverage home converter (Equations 13, 30 and 40). Under the first two stock policies, $A a A$ and $(s, S)$, Equations 13 and 30 have volume units, while for the utS policy equation 40 has time units. Amplifying the time inventory coverage under the utS stock control policy helps to easily initialize the corresponding SD model at steady state, again, a point utterly crucial to the validity of simulation results. 


\subsection{Performance measurement}

The assessment of supply chain performance takes place through the factory stock amplification ratio $(F S A R)$. Figure 7 shows the stock and flow diagram and Table A4 (Appendix A) the corresponding equations of the SD model sector that computes the $F S A R$, in order to assess the independent and joint effects of judgemental forecast and order adjustments on supply chain performance.

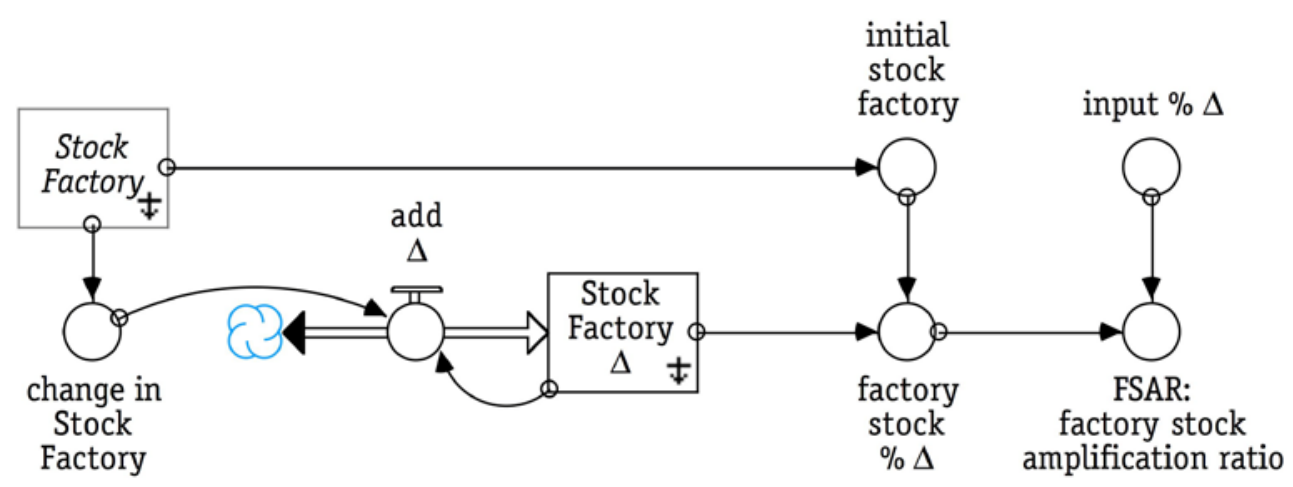

Figure 7. Computing the factory stock amplification ratio (FSAR)

Sterman (2000) defines the amplification ratio as "the ratio of the maximum change in the output to the maximum change in the input (p. 673)". Accordingly, the Stock Factory $\Delta$ stock on Figure 7 (Equation 49, Table A4) accumulates the maximum change in the Stock Factory via the add $\Delta$ flow (Equation 50). This flow feeds the Stock Factory $\Delta$ stock, incrementally, only when judgmental forecast and/or order adjustments cause Stock Factory to change and to reach a level higher than its previous one. Subsequently, the factory stock $\% \Delta$ converter (Equation 52) becomes the numerator of the FSAR (Equation 53). Its denominator is the auxiliary constant parameter input $\% \Delta=0.25$ (Equation 55) because all the judgmental forecast and/or order adjustment interventions in this study, 
equally spaced in time, entail either a downward or an upward adjustment of $25 \%$ change in the input, always independent from any previous change.

\section{Analysis of results}

Our results have been summarised as follows: each FSAR figure shows five graphs that reflect different experimental conditions, also summarised within each figure. Within each figure, graphs $a$ and $b$ summarise the independent (within only one stage at a time: Client, Home, Factory) intervention effects on FSAR. Each line represents results for a different stock control policy, and each point represents a run with a particular type of intervention, details of which are presented on the right hand side of each graph. Switch 1 indicates an alternate plus-minus adjustment pattern or an only positive adjustment pattern. Switch -1 indicates an alternate minus-plus adjustment pattern or an only negative adjustment pattern. Similarly, graphs $c$ and $d$ show the 2-way interaction effects of judgemental interventions at: Client \& Home (C H), Client \& Factory (C F), Home \& Factory (H F). On the $x$-axis the stages at which we intervene are preceded by a plus $(+)$ or minus (-) sign, for the switch 1 and switch -1 respectively, to indicate the type of adjustment that has been considered for the stage under concern. Finally, graph $e$ shows the effects of intervening in all stages of the SC (with a similar notation used on the $x$ axis).

Figures on time domain results indicate, for the specified control parameter combinations, the inventory level in units over time at each of the supply chain stages considered (Client, Home and Factory) for all three stock control policies investigated in our experiment. 
Overall, the results indicate that judgemental interventions have a considerable effect on supply chain performance. This is true for both forecast and order adjustments. The impact varies according to the intervention point in the supply chain.

Relatively speaking, the judgemental forecast adjustments seem to have the most prominent effects, while the judgemental order adjustments appear to have the least prominent effects on the Factory Stock Amplification Ratio. This implies that it would be difficult for managers to compensate for the effects of judgemental forecast adjustments through judgementally adjusting replenishment orders.

Figures $8 a$ and $b$ show the independent effects of judgemental forecast adjustments at the $C, H$ and $F$ stages. Irrespective of the mixed intervention pattern assumed, adjustments that take place at the $C$ stage result in the highest FSAR. This is true for all stock control policies considered. Conversely, reducing the number of stages between the forecast adjustment intervention point and the Factory stock causes its amplification to decline. That is, the impact of the forecast adjustments is less prominent as the intervention point moves upstream in the supply chain, from Client to Home to Factory.

Figures $8 c$ and $d$ assess the effects of adjustments applied concurrently at two intervention points. The results are consistent with those discussed above: adjustments that take place at the Client stage have the greatest impact. The AaA policy appears to be the least sensitive to the location of the intervention points considered. This issue is further discussed later in this section. 


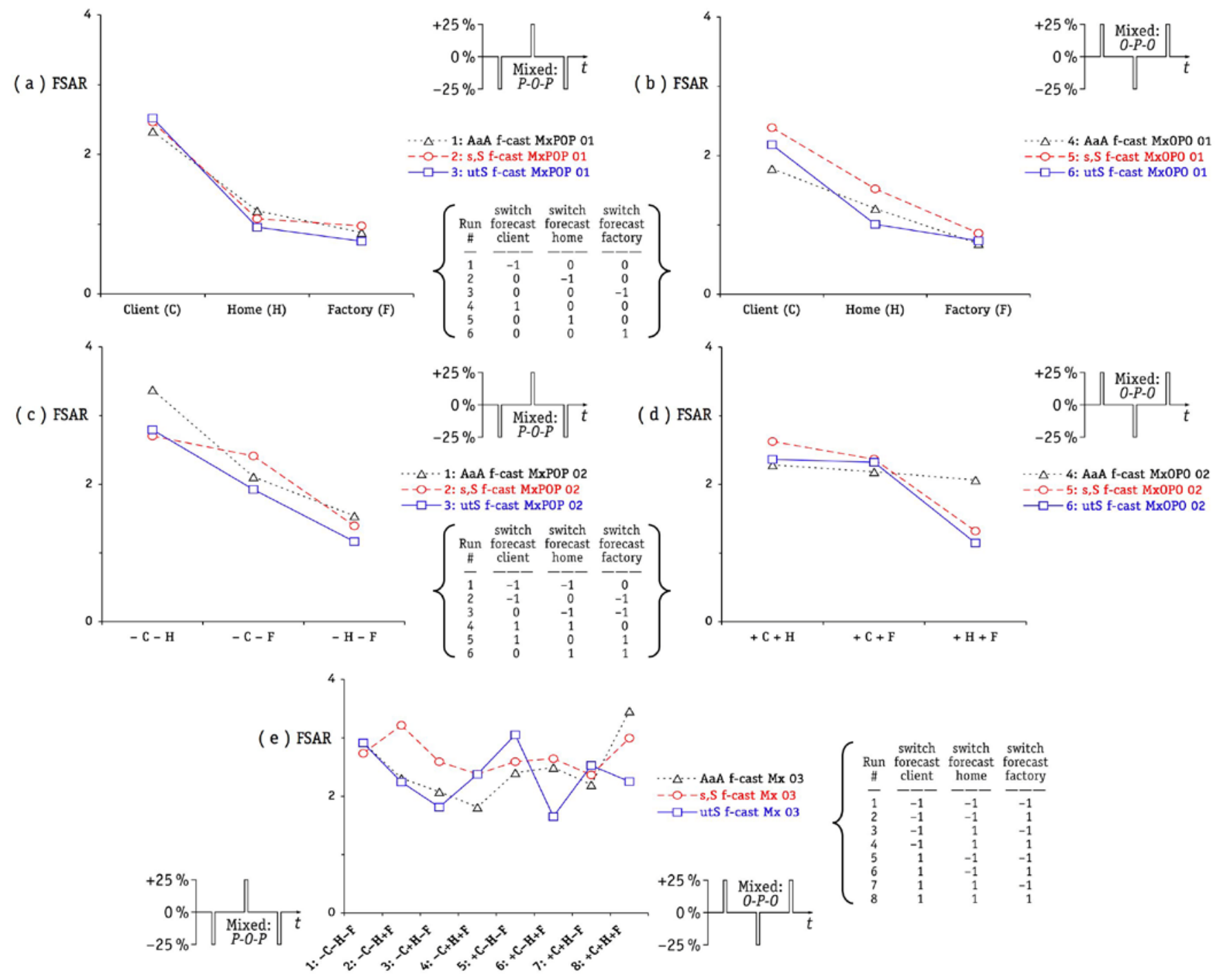

Figure 8. FSAR results of client, home and factory sector forecast adjustments, with mixed optimism $(O)$ and pessimism $(P)$, under the $A o A,(s, S)$ and utS stock policies

The results shown in Figure $8 e$, where forecast adjustments are performed in all three stages of the supply chain, indicate a rather variable behaviour of the stock control policies depending on the combination of optimistic and pessimistic adjustments at the various stages. However, they do demonstrate that, for each specific combination, the stock control policy affects the FSAR. We also further elaborate on this issue later on in this section. 


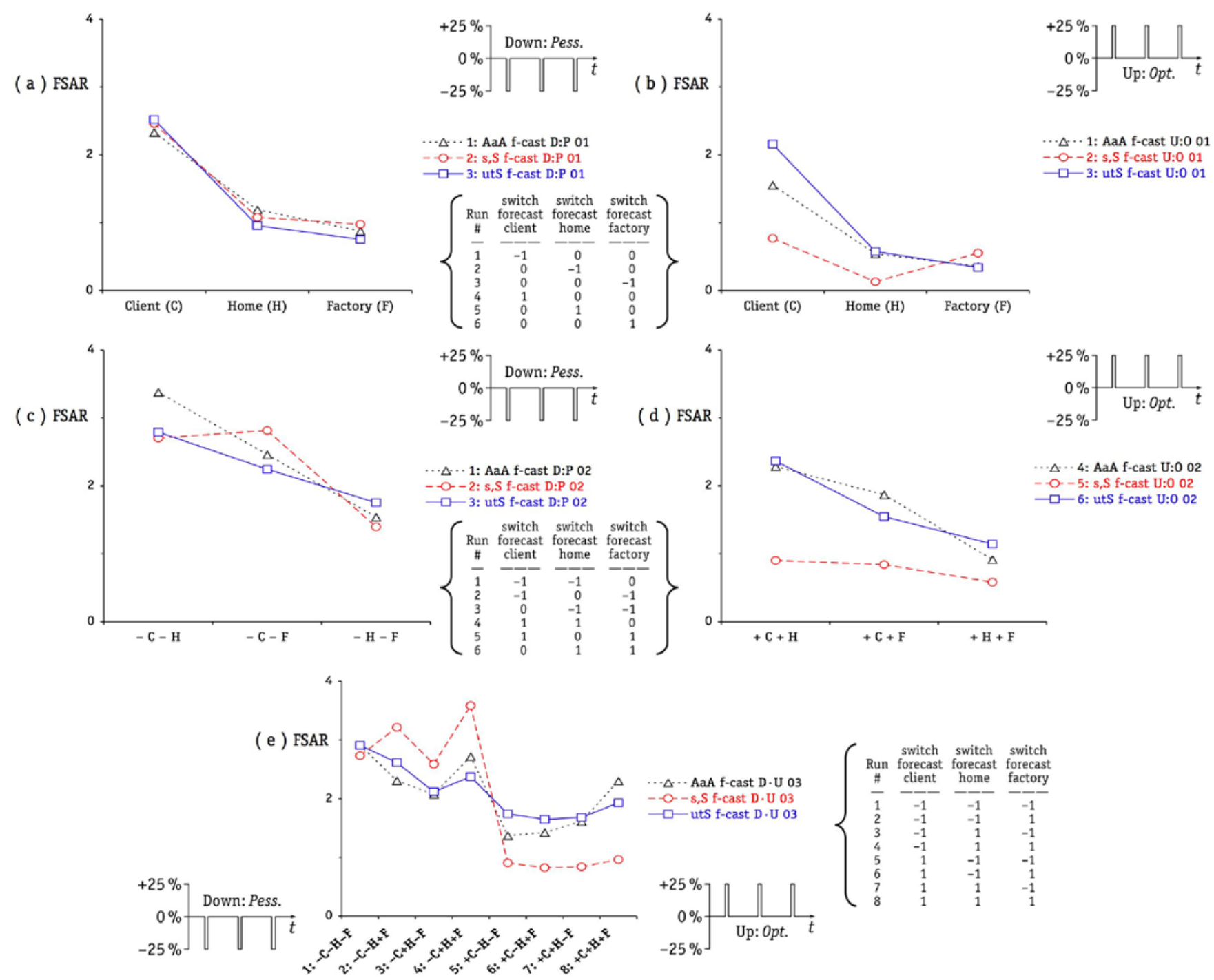

Figure 9. FSAR results of client, home and factory sector forecast adjustments, with persistent optimism $(O)$ and pessimism $(P)$, under the $A o A,(s, S)$ and utS stock policies

The results presented in the Figure 9 confirm overall those discussed above with the only difference related to the response of the $(s, S)$ stock policy which is highly sensitive to pessimistic adjustments (especially at the Client stage). On Figure $9 e$, as we move from persistent pessimism to persistent optimism at the Client stage, the FSAR drops dramatically. The implicit order batching design of this policy introduces a delay in the system's upwards response, so if the Factory stock has been depleted due to pessimistic 
forecast adjustments then it takes longer for this policy (as compared to the other two) to rebuild inventory.

Figure 10 shows the results of the last run of Figure $9 e$ (persistent optimism reigns across all stages of the supply chain) for all three stock control policies. This figure demonstrates the reason we chose the FSAR as a proxy to assess the overall supply chain performance. In all three cases, the Factory stock clearly shows the highest amplification, irrespective of the underlying stock policy. The Home stock rates second in terms of amplitude while the Client stock appears as the most resistant to these persistent optimistic adjustments. In the case of the Home stock (line no. 2) there are indications of phase-doubling particularly in the $A a A$ and $u t S$ policies but this is somewhat subdued in the case of the $(s, S)$ stock policy.

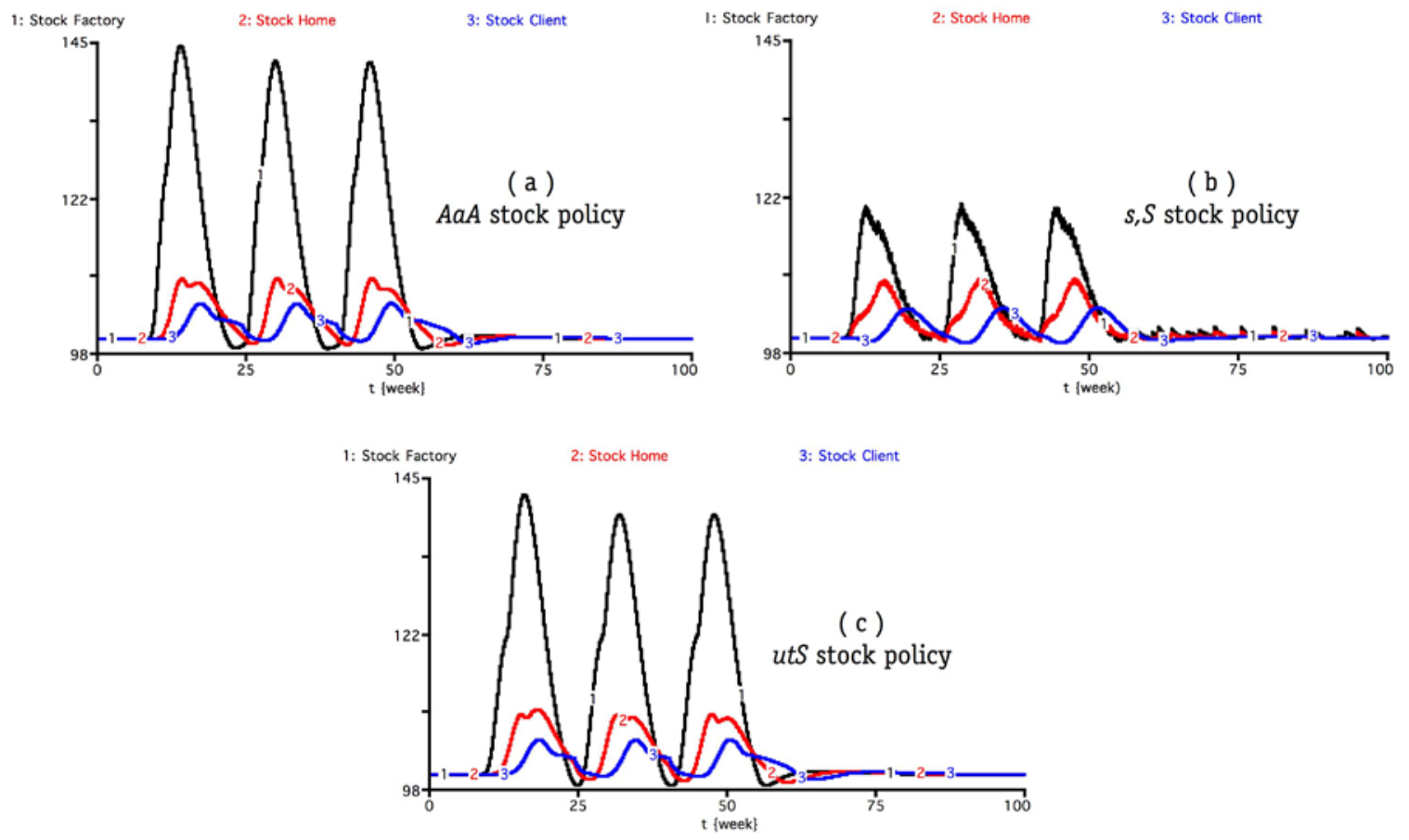

Figure 10. The time-domain results of run $\# 8$ on Figure 9e 
Figure $10 b$ shows that the initial equilibrium of the $(s, S)$ stock policy driven system is an unstable one. This is very easy to understand if one looks at Equation 33 (Table A2). The if-then-else structure of the Order from Factory converter creates sharp discontinuities that do not allow the system to return to its initial unstable equilibrium. In addition, Figures $10 a$ and $c$ clearly show that the highest FSAR emanates from the initial 'shock' that the first forecast adjustment introduces into the system. Subsequent judgemental forecast adjustments continue to create 'shocks' but their amplification amplitude is not as great as the initial one. This downward sloping trend that the FSAR shows in the time domain is not always followed, as demonstrated by other experimental results not shown in this paper. Our electronic companion presents cases where subsequent adjustments may increase the factory stock amplification progressively, thereby creating an upward trend in FSAR.

Figure 11 shows the effects of judgemental order adjustments under a mixed (Optimistic and Pessimistic) intervention mechanism. Graph 11e shows the resistance of the $(s, S)$ policy to order adjustments across all mixed optimistic and pessimistic conditions. Conversely, the other two stock policies (AaA and $u t S$ ) appear sensitive to all optimistic and to all pessimistic mixed order adjustments and less sensitive to the scenarios that deviate from those extremes. 


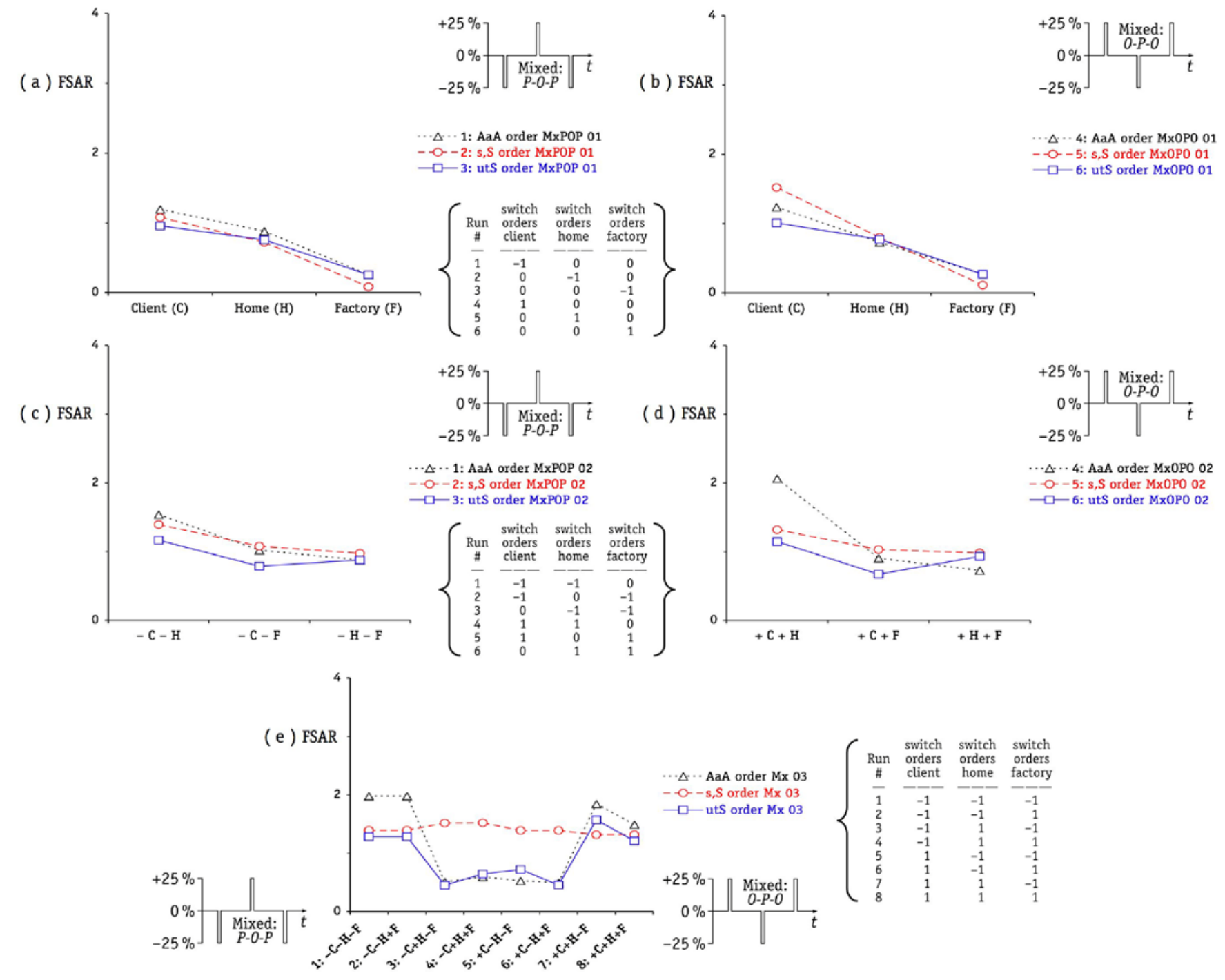

Figure 11. FSAR results of client, home and factory sector order adjustments, with mixed optimism $(O)$ and pessimism $(P)$, under the $A o A,(s, S)$ and $u t S$ stock policies

Figure 12 shows the interaction between optimistic forecast adjustments and persistent, either optimistic or pessimistic, order adjustments. The most important results are as follows: under conditions of optimistic forecasts in all sectors and persistent optimistic and pessimistic order adjustments the $(s, S)$ inventory policy seems to be the least sensitive to them. On all graphs of Figure 12, the FSAR is the lowest under the $(s, S)$ 
policy. Perhaps this is good news for SAP users since the inventory modules of the ERP package under concern is explicitly based on $(s, S)$ policies.

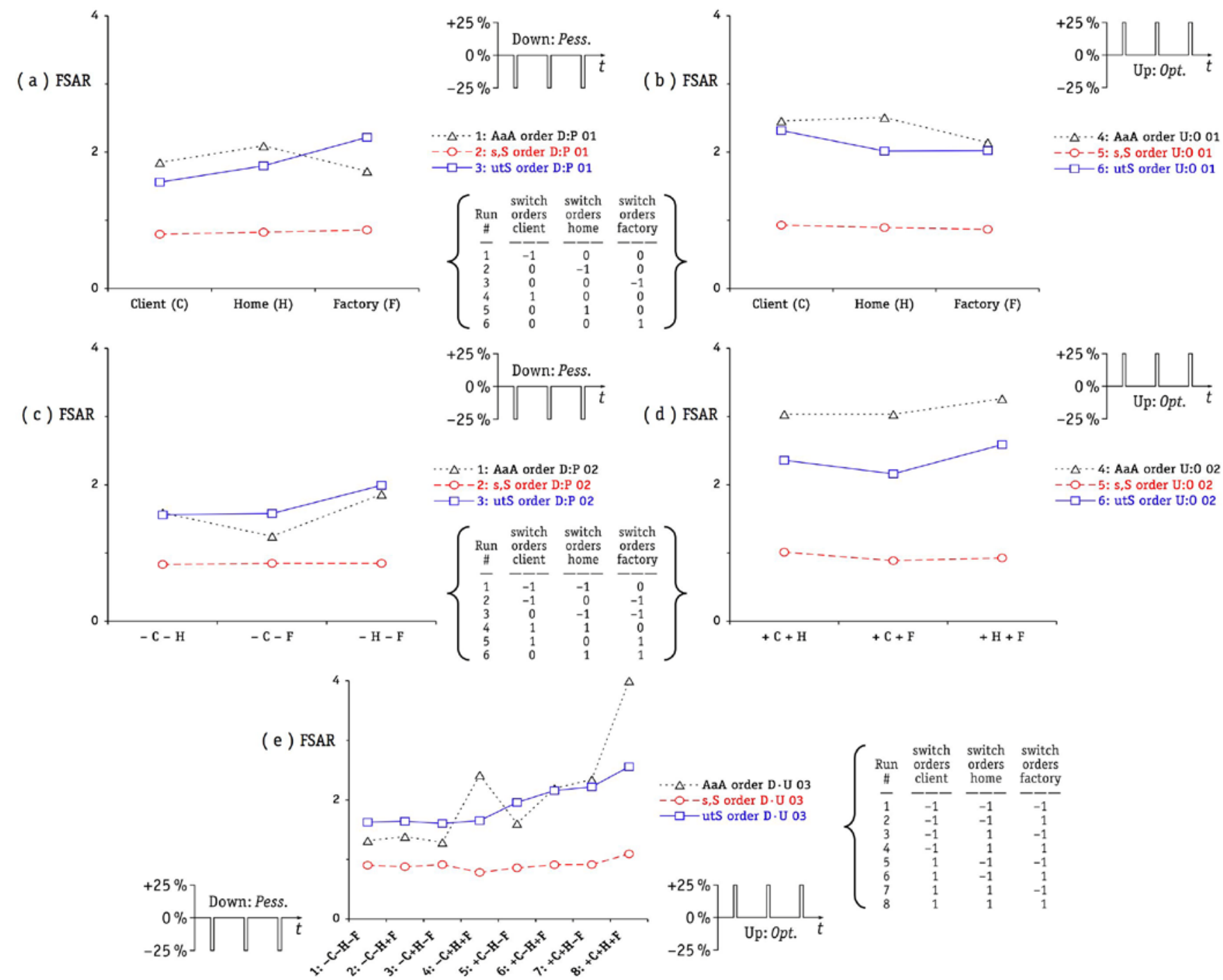

Figure 12. FSAR results of the interaction among all-sector optimistic forecast and allsector order adjustments with persistent optimism $(O)$ and pessimism $(P)$, under the $A o A$, $(s, S)$ and $u t S$ stock policies

In the time domain, the phase plot of Figure 13d shows the relation between the Factory Stock and its autocorrelation $(r)$, sampled once every five weeks. On the horizontal axis, $y$ represents the Factory Stock. Although the axis is bounded on the lower side at 0, the 
scale has been extended only for presentational purposes. Phase plots hide the time dimension, but the little arrows on Figure 13d show how the relation between Factory Stock and $r$ evolves through time. The wildly oscillating $r$ suggests that the highly interdependent variables in supply chains may be too ill-behaved to assess with mathematical models.
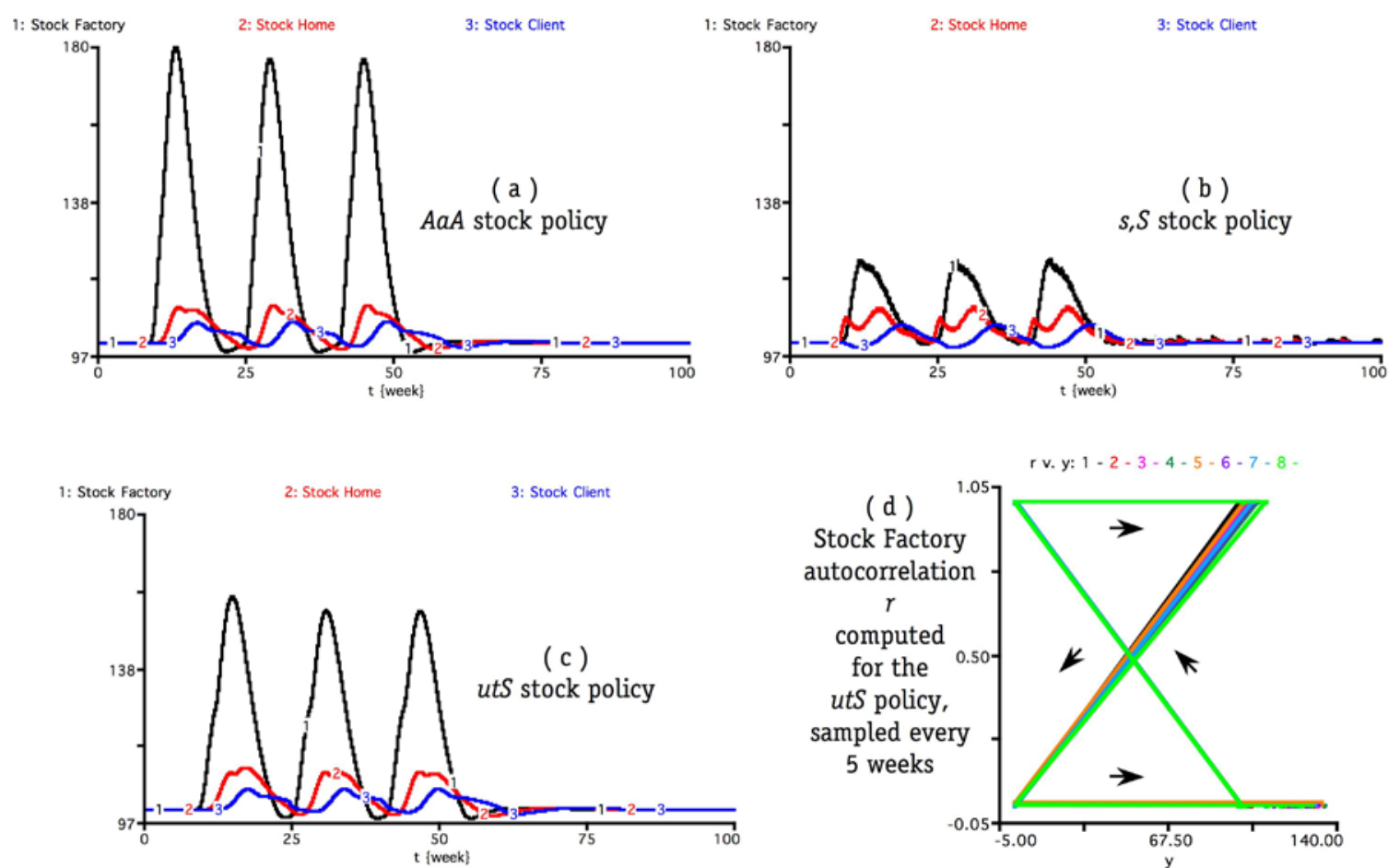

Figure 13. The time-domain results of run \#8 on Figure 12e

It is worth noting that, with regards to the phase-doubling component of the bullwhip effect, contrary to the results presented in Figure 10, where the Home stock shows signs of phase doubling under the AaA and utS stock control policies, on Figure 13 the Home stock amplification shows clear signs of phase doubling under the $(s, S)$ stock policy. 


\section{Conclusions and extensions}

Pioneered by Forrester $(1958,1961)$ and influenced by engineering control theory, SD calls for formal simulation modelling that provides a rigorous understanding of system behaviour. Simulation modelling has become an essential research tool in social science because "people's intuitive predictions about the dynamics of complex systems are systematically flawed (Sterman, 1994, p. 178)", mostly because of our bounded rationality. SD is a modelling method with high descriptive ability and theory building potential (Davis et al, 2007; Georgantzas, 2001; Lane and Schwaninger, 2008).

Adapted predominantly from Sterman (2000, Ch. 17 and 18) and other colleagues, who model supply chains with SD (Barlas and Ozevin; 2004; Georgantzas, 2003, 2009; Yasarcan and Barlas 2005), the SD model sectors in this study explain the sources of oscillation, amplification and phase lag generally seen in client-supplier chains; phenomena which executives at 3M, Bristol-Myers Squibb, Hewlett-Packard and P\&G collectively call the bullwhip effect (Lee et al, 1997b). Locally rational policies that create smooth and stable adjustment of individual business units can, through their interaction with other functions and firms, cause oscillation and instability, i.e. bullwhiptype dynamics. The models incorporate policy parameters pertinent to decision making and timing that allow testing the sensitivity of client-supplier value chains to exogenous judgmental forecast and order adjustments. The results reveal policies that managers and their suppliers can use to improve performance. 
Our study indicates that judgemental interventions may have a substantially adverse effect on supply chain performance if undertaken unnecessarily. Judgemental forecast adjustments have more prominent effects than judgemental order adjustments on the Factory Stock Amplification Ratio. To the best of our knowledge, this differential effect has not been reported previously in the literature. As discussed in the previous section, this finding implies that it may be more difficult for managers to compensate for the effects of judgemental forecast adjustments through judgementally adjusting replenishment orders.

Our investigation also shows that the impact of the forecast and order adjustments is less prominent as the intervention point moves upstream in the supply chain, from Client to Home to Factory. For the Anchor-and-Adjust (AaA) policy, this finding is consistent with results from system dynamics studies of multi-echelon inventory systems as far back as Forrester (1958). For the order-up-to-level S (utS) policy, the result is consistent with the amplification of variance through the supply chain, quantified by Lee at al (2000), although his paper did not address the issue of judgemental adjustments to forecasts or orders. For the re-order point, order-up-to-level $(s, S)$ policy, we have provided new results on the effect of adjustments on the Factory Stock Amplification Ratio.

Most previous papers on the Bullwhip Effect have focused on the order-up-to-level $S$ policy. In this paper, we have shown that the $(s, S)$ policy is less sensitive to order and forecast adjustments than the order-up-to $S$ policy (utS). The only exception to this result is that $(s, S)$ systems are more adversely affected by pessimistic forecast adjustments. In 
this case, the implicit order batching means that it takes longer for this system to rebuild inventory. The findings on the $(s, S)$ system are important, as this policy is frequently adopted in practice.

\subsection{Further research}

The research described in this paper constitutes an initial attempt to explore the effects of judgemental interventions on supply chain performance. Naturally, there are many avenues for further contributions in this area. In particular, the standardisation of the magnitude of the adjustments to $25 \%$ is viewed as rather restrictive. We have attempted to capture a wide range of possible interventions in terms of the direction of the forecast and order adjustments and the point of intervention in the supply chain. However, the magnitude of such adjustments has not been introduced as a control parameter. Although some empirical justification has been offered to support our choice, further research should look at the effect that the size of the adjustments may have on supply chain dynamics. In addition, demand has been assumed to be deterministic and constant for the purposes of our study. Experimentation with variable demand and/or deterministic demand patterns that may be associated with ramp or step changes over time should offer valuable insights on the performance of the system. Moreover, we have assumed that each stage in the supply chain employs the same stock control policy. Perhaps under some circumstances a more realistic representation of the problem would involve a combination of such policies. Finally, other stock control policies could have been introduced as well. The re-order point $s$, order quantity $Q(s, Q)$ policy for example would 
enable a more thorough investigation of the effects of order batching in conjunction with judgemental adjustments.

Future research must necessarily render both the judgemental forecast and the judgemental order adjustments endogenous. Depending on managers' own mood desposedness towards pessimism and/or optimism as well that of the organisation they are affiliated with or manage, they may respond differentially to an initial system 'shock'. Consequently, they may alter their subjective interventions on forecast and replenishment orders according to how initial 'shocks' shape their personalised organisational goals. System Dynamics can play a crucial role in evaluating the impact of any learning effects (i.e. the adjustments get better over time) in the process of intervening with forecasts and/or orders. No evidence of such effects has been found through empirical studies and this constitutes a very promising area for further research.

Most importantly, our research focused on the implications of people making an adjustment when such adjustment is not needed. That is to say, in all the experimental conditions considered the adjustments are unwarranted, as there is no change in the underlying demand pattern. This allows for an assessment of the effect of un-necessary forecast adjustments on the supply chain. Although such a scenario is realistic and supported by empirical evidence, further research should also look at the effect of fully or partially warranted adjustments to forecasts and/or orders, in response to changes in the demand patterns or to other organisational factors. 


\section{References}

Akkermans H and Dellaert N (2005). The rediscovery of industrial dynamics: the contribution of system dynamics to supply chain management in a dynamic and fragmented world. System Dynamics Review 21: 173-186.

Barlas Y and Ozevin MG (2004). Analysis of stock management gaming experiments and alternative ordering formulations. Systems Research and Behavioural Science 21: 439-470.

Blattberg RC and Hoch SJ (1990). Database models and managerial intutition: 50\% model + 50\% manager. Management Science 36: 887-899.

Cachon GP and Lariviere M (1999). Capacity allocation using past sales: when to turn-and-earn. Management Science 45: 685-703.

Chen F, Drezner Z, Ryan JK and Simchi-Levi D (2000a). Quantifying the bullwhip effect in a simple supply chain: the impact of forecasting, lead times, and information. Management Science 46: 436-443.

Chen F, Ryan JK and Simchi-Levi D (2000b). The impact of exponential smoothing forecasts on the bullwhip effect. Naval Research Logistics 47: 269-286.

Cheung KL and Zhang AX (1999). The impact of inventory information distortion due to customer order cancellations. Naval Research Logistics 46: 213-231.

Clark TE and McCracken MW (2001). Tests of equal forecast accuracy and encompassing for nested models. Journal of Econometrics 105: 85-110.

Clark TE and McCracken MW (2005). Evaluating direct multi-step forecasts. Econometric Reviews 24: 369-404.

Croson R and Donohue K (2005). Upstream versus downstream information and its impact on the bullwhip effect. System Dynamics Review 21: 249-260.

Davis JP, Eisenhardt KM and Bingham C (2007). Developing theory through simulation methods. Academy of Management Review 32: 480-499.

Eroglu C (2006). An investigation of accuracy, learning and biases in judgmental adjustments of statistical forecasts. PhD thesis, Ohio State University, USA.

Eroglu C and Croxton KL (2010). Biases in judgmental adjustments of statistical forecasts: the role of individual differences. International Journal of Forecasting 26: 116-133.

Fildes R, Goodwin P, Lawrence M and Nikolopoulos K (2009). Effective forecasting and judgmental adjustments: an empirical evaluation and strategies for improvement in supplychain planning. International Journal of Forecasting 25: 3-23.

Forrester JW (1958). Industrial dynamics - a major breakthrough for decision makers. Harvard Business Review 36: 37-66. 
Forrester JW (1961). Industrial dynamics. MIT Press: Cambridge, MA; currently available from Pegasus Communications: Waltham, MA.

Franses PH (2007). Does experts' adjustment to model-based forecasts contribute to forecast quality? Econometric Institute Report 2007-37, Erasmus University Rotterdam, The Netherlands.

Franses PH and Legerstee R (2009). Properties of expert adjustments on model-based SKU-level forecasts. International Journal of Forecasting 25: 35-47.

Gavirneni S (2006). Price fluctuations, information sharing and supply chain performance. European Journal of Operational Research 174: 1651-1663.

Georgantzas NC (2001) Simulation modeling. In M Warner (Ed.), International Encyclopedia of Business and Management, 2nd ed. Thomson Learning: London, UK, pp. 5861-5872.

Georgantzas NC (2003). Tourism dynamics: Cyprus' hotel value chain and profitability. System Dynamics Review 19: 175-212.

Georgantzas, NC (2009) Scenario-driven planning with system dynamics. In B Meyers (Ed.), Encyclopedia of Complexity and System Science. Entry \# 573, 23 pgs.

Kleijnen JPC and Smits MT (2003). Performance metrics in supply chain management. Journal of the Operational Research Society 54: 507-514.

Kolassa S, Shütz W, Boylan JE and Syntetos AA (2008). Judgemental changes to forecasts: higher inventories, unchanged out-of-stocks. $28^{\text {th }}$ International Symposium on Forecasting, Nice, France.

Lane DC and Schwaninger M (2008). Theory building with system dynamics: topic and research contributions. Systems Research and Behavioral Science 25(4): 439-445.

Lee HL, Padmanabhan V and Whang S (1997a). Information distortion in a supply chain: the Bullwhip effect. Management Science 43: 546-558.

Lee HL, Padmanabhan V, Whang S (1997b). The Bullwhip Effect in supply chains. Sloan Management Review 38: 93-102.

Lee HL, So KC and Tang CS (2000). The Value of information sharing in a two-level supply chain. Management Science 46: 626-643.

Otto A and Kotzab H (2003). Does supply chain management really pay? Six perspectives to measure the performance of managing a supply chain. European Journal of Operational Research 144: 306-320.

Paik S-K and Bagchi PK (2007). Understanding the causes of the bullwhip effect in a supply chain. International Journal of Retail and Distribution Management 35: 308-324. 
Potter A and Disney SM (2006). Bullwhip and batching: an exploration. International Journal of Production Economics 104: 408-418.

Pujawan IN (2004). The effect of lot sizing rules on order variability. European Journal of Operational Research 159: 617-635.

Reiner G and Fichtinger J (2009). Demand forecasting for supply processes in consideration of pricing and market information. International Journal of Production Economics 118: 5562.

Richmond B (2009). iThink ${ }^{\circledR}$ Software (version 9.1.3). iSee Systems ${ }^{\mathrm{TM}}{ }^{\mathrm{T}}$ Lebanon NH.

Saeed K (2009). Can trend forecasting improve stability in supply chains? A response to Forrester's challenge in Appendix L of Industrial Dynamics. System Dynamics Review 25: 63-78.

Sterman JD (1994). Learning in and about complex systems. System Dynamics Review 10: 291330.

Sterman JD (2000). System Dynamics: systems thinking and modeling for a complex world. Irwin McGraw-Hill: Boston, MA.

Syntetos AA and Boylan JE (2008). Demand forecasting adjustments for service-level achievement. IMA Journal of Management Mathematics 19: 175-192.

Syntetos AA, Boylan JE and Disney SM (2009a). Forecasting for inventory planning: a 50-year review. Journal of the Operational Research Society 60 (S1): 149-160.

Syntetos AA, Nikolopoulos K and Boylan JE (2010). Judging the judges through accuracyimplication metrics: the case of inventory forecasting. International Journal of Forecasting 26: $134-143$.

Syntetos AA, Nikolopoulos K, Boylan JE, Fildes R and Goodwin P (2009b). The effects of integrating management judgement into intermittent demand forecasts. International Journal of Production Economics 118: 72-81.

Wong CY, El-Beheiry MM, Johansen J and Hvolby HH (2007). The implications of information sharing on bullwhip effects in a toy supply chain. International Journal of Risk Assessment and Management 7: 4-18.

Yasarcan H and Barlas Y (2005). A generalized stock control formulation for stock management problems involving composite delays and secondary stocks. System Dynamics Review 21: 33-68.

Zhang X (2004). Evolution of ARMA demand in supply chains. Manufacturing \& Services Operations Management 6: 195-198. 


\section{APPENDIX A: Model equations}

\begin{tabular}{|c|c|}
\hline Sector 2.a: Home stock level (state) or stock variables \{unit\} & Eq. \# \\
\hline Stock Home $(\mathrm{t})=$ Stock Home $(\mathrm{t}-\mathrm{dt})+($ to stock home - ship to client $) * \mathrm{dt}$ & (1) \\
\hline INIT Stock Home $=$ demand home $*$ time to order home $\{\mathrm{SKU}\}$ & $(1.1)$ \\
\hline WIP A Home $(\mathrm{t})=$ WIP A Home $(\mathrm{t}-\mathrm{dt})+($ receive home - to WIP B home $) * \mathrm{dt}$ & (2) \\
\hline INIT WIP A Home $=$ Stock Home $\{$ SKU $\}$ & $(2.1)$ \\
\hline WIP B Home $(\mathrm{t})=$ WIP B Home $(\mathrm{t}-\mathrm{dt})+($ to WIP B home - to WIP C home $) * \mathrm{dt}$ & (3) \\
\hline INIT WIP B Home = Stock Home $\{$ SKU $\}$ & $(3.1)$ \\
\hline WIP C Home $(\mathrm{t})=$ WIP C Home $(\mathrm{t}-\mathrm{dt})+($ to WIP C home - to stock home $) * \mathrm{dt}$ & $(4)$ \\
\hline INIT WIP C Home = Stock Home $\{$ SKU $\}$ & $(4.1)$ \\
\hline \multicolumn{2}{|l|}{ Sector 2.a: Home stock flow or rate variables \{unit\} } \\
\hline receive home $=$ MAX (0, ship to home) $\{$ SKU/week $\}$ & (5) \\
\hline ship to client = MIN (need for client, Stock Home / time to order home) $\{$ SKU/week & (6) \\
\hline to stock home = MAX (0, WIP C Home / (lead time home / 3)) $\{$ SKU/week $\}$ & (7) \\
\hline to WIP B home $=\operatorname{MAX}(0$, WIP A Home $/($ lead time home $/ 3))\{$ SKU/week $\}$ & (8) \\
\hline to WIP C home = MAX (0, WIP B Home / (lead time home / 3) $)\{$ SKU/week $\}$ & (9) \\
\hline \multicolumn{2}{|l|}{ Sector 2.a: Home stock auxiliary or converter variables and constants \{unit\} } \\
\hline adjust SC home = gap SC home $/$ time to order home $\{$ SKU/week $\}$ & $(10)$ \\
\hline adjust stock home = stock gap home / adjust stock home time $\{$ SKU/week $\}$ & $(11)$ \\
\hline adjust stock home time $=1$ \{week $\}$ & $(12)$ \\
\hline coverage home $=$ lead time home $*$ Est D Home $\{S K U\}$ & (13) \\
\hline gap SC home = coverage home - net SC home $\{$ SKU $\}$ & (14) \\
\hline lead time home $=3\{$ week $\}$ & (15) \\
\hline need for client $=$ demand home $+($ Backlog Home $/$ time to order home $)\{$ SKU/week $\}$ & (16) \\
\hline net SC home = Backlog Factory + SC home $\{$ SKU $\}$ & (17) \\
\hline net stock home $=$ Stock Home - Backlog Home $\{$ SKU $\}$ & (18) \\
\hline order from factory $=\operatorname{MAX}(0,($ Est D Home + adjust stock home + adjust SC home $)$ \{SKU/week $\}$ & (19) \\
\hline SC home = WIP A Home + WIP B Home + WIP C Home $\{$ SKU $\}$ & (20) \\
\hline stock gap home $=$ demand home - net stock home $/$ adjust stock home time $\{$ SKU/week $\}$ & $(21)$ \\
\hline time to order home $=1\{$ week $\}$ & $(22)$ \\
\hline \multicolumn{2}{|l|}{ Sector 2.b: Home backlog level (state) or stock variables \{unit\} } \\
\hline Est D Home $(\mathrm{t})=$ Est $\mathrm{D}$ Home $(\mathrm{t}-\mathrm{dt})+($ alter est $\mathrm{D}$ home $) * \mathrm{dt}$ & (23) \\
\hline INIT Est D Home = demand home $\{$ SKU $/$ week $\}$ & $(23.1)$ \\
\hline \multicolumn{2}{|l|}{ Sector 2.b: Home backlog flow or rate variables $\{$ unit\} } \\
\hline alter backlog home $=$ demand home - ship to client $\{$ SKU/week $\}$ & $(24)$ \\
\hline \multicolumn{2}{|l|}{ Sector 2.c: Home forecast level (state) or stock variables $\{$ unit\} } \\
\hline Est D Home $(\mathrm{t})=$ Est $\mathrm{D}$ Home $(\mathrm{t}-\mathrm{dt})+($ alter est $\mathrm{D}$ home $) * \mathrm{dt}$ & $(25)$ \\
\hline INIT Est D Home = demand home $\{$ SKU $/$ week $\}$ & $(25.1)$ \\
\hline \multicolumn{2}{|l|}{ Sector 2.c: Home forecast flow or rate variables \{unit\} } \\
\hline alter est $\mathrm{D}$ home = demand gap home $/$ alter est $\mathrm{D}$ time home $\{\mathrm{SKU} /$ week/week $\}$ & $(26)$ \\
\hline \multicolumn{2}{|l|}{ Sector 2.c: Home forecast auxiliary or converter variables and constants $\{$ unit $\}$} \\
\hline alter est $\mathrm{D}$ time home $=5\{$ week $\}$ & (27) \\
\hline demand gap home $=$ demand home - Est D Home $\{$ SKU/week $\}$ & $(28)$ \\
\hline demand home $=$ order from home $\{$ SKU/week $\}$ & (29) \\
\hline
\end{tabular}

Table A1. The home $(H)$ supply-chain model sector equations, under the AoA stock policy 


\begin{tabular}{|c|c|}
\hline Sector 2.a: Home stock level (state) or stock variables $\{$ unit $\}$ & Eq. \# \\
\hline \multicolumn{2}{|l|}{ Identical with Eqs 1 through 4.1 on Table A1 } \\
\hline \multicolumn{2}{|l|}{ Sector 2.a: Home stock flow or rate variables $\{$ unit $\}$} \\
\hline \multicolumn{2}{|l|}{ Identical with Eqs 5 through 9 on Table A1 } \\
\hline \multicolumn{2}{|l|}{ Sector 2.a: Home stock auxiliary or converter variables and constants $\{$ unit\} } \\
\hline coverage home $=$ lead time home $*$ Est D Home $\{$ SKU $\}$ & $(30)$ \\
\hline lead time home $=3\{$ week $\}$ & $(31)$ \\
\hline need for client $=$ demand home $+($ Backlog Home $/$ order time home $)\{$ SKU/week $\}$ & $(32)$ \\
\hline $\begin{array}{l}\text { order from factory }=\text { IF (stock position home }<=\text { s home) THEN (MAX (0, (order up to S home - stock } \\
\text { position home) / order time home) ELSE (0) }\{\text { SKU/week }\}\end{array}$ & (33) \\
\hline order time home $=1\{$ week $\}$ & $(34)$ \\
\hline order up to $\mathrm{S}$ home $=\mathrm{s}$ home + Est $\mathrm{D}$ Home $*$ order time home $\{\mathrm{SKU}\}$ & (35) \\
\hline s home $=$ coverage home + safety stock home $\{$ SKU $\}$ & $(36)$ \\
\hline safety stock home $=100\{$ SKU $\}$ & $(37)$ \\
\hline SC home $=$ WIP A Home + WIP B Home + WIP C Home & (38) \\
\hline stock position home $=$ Stock Home + SC home + Backlog Factory - Backlog Home $\{$ SKU $\}$ & $(39)$ \\
\hline \multicolumn{2}{|l|}{ Sector 2.b: Home backlog level (state) or stock variables \{unit\} } \\
\hline \multicolumn{2}{|l|}{ Identical with Eqs 23 through 23.1 on Table A1 } \\
\hline \multicolumn{2}{|l|}{ Sector 2.b: Home backlog flow or rate variables $\{$ unit $\}$} \\
\hline \multicolumn{2}{|l|}{ Identical with Eq. 24 on Table A1 } \\
\hline \multicolumn{2}{|l|}{ Sector 2.c: Home forecast level (state) or stock variables \{unit\} } \\
\hline \multicolumn{2}{|l|}{ Identical with Eqs 25 through 25.1 on Table A1 } \\
\hline \multicolumn{2}{|l|}{ Sector 2.c: Home forecast flow or rate variables $\{$ unit $\}$} \\
\hline \multicolumn{2}{|l|}{ Identical with Eq. 26 on Table A1 } \\
\hline \multicolumn{2}{|l|}{ Sector 2.c: Home forecast auxiliary or converter variables and constants $\{$ unit $\}$} \\
\hline Identical with Eqs 27 through 29 on Table A1 & \\
\hline
\end{tabular}

Table A2. The home $(H)$ supply-chain model sector equations, under the $(s, S)$ stock policy 


\begin{tabular}{|c|c|}
\hline Sector 2.a: Home stock level (state) or stock variables $\{$ unit\} & Eq. \# \\
\hline \multicolumn{2}{|l|}{ Identical with Eqs 1 through 4.1 on Table A1 } \\
\hline \multicolumn{2}{|l|}{ Sector 2.a: Home stock flow or rate variables $\{$ unit $\}$} \\
\hline \multicolumn{2}{|l|}{ Identical with Eqs 5 through 9 on Table A1 } \\
\hline \multicolumn{2}{|l|}{ Sector 2.a: Home stock auxiliary or converter variables and constants $\{$ unit\} } \\
\hline coverage home $=$ lead time home $+($ alter est $\mathrm{D}$ time home - lead time home $)\{$ week $\}$ & $(40)$ \\
\hline gap home = order up to S home - stock position home $\{$ SKU $\}$ & (41) \\
\hline lead time home $=3\{$ week $\}$ & $(42)$ \\
\hline need for client $=$ demand home $+($ Backlog Home $/$ time to order home $)\{$ SKU/week $\}$ & $(43)$ \\
\hline order from factory = MAX (0, gap home / time to order home) $\{$ SKU/week $\}$ & (44) \\
\hline order up to S home = coverage home $*$ Est D Home $\{$ SKU $\}$ & $(45)$ \\
\hline SC home = WIP A Home + WIP B Home + WIP C Home $\{$ SKU $\}$ & $(46)$ \\
\hline stock position home $=$ Stock Home + SC home + Backlog Factory - Backlog Home $\{$ SKU $\}$ & $(47)$ \\
\hline time to order home $=1\{$ week $\}$ & (48) \\
\hline \multicolumn{2}{|l|}{ Sector 2.b: Home backlog level (state) or stock variables \{unit\} } \\
\hline \multicolumn{2}{|l|}{ Identical with Eqs 23 through 23.1 on Table A1 } \\
\hline \multicolumn{2}{|l|}{ Sector 2.b: Home backlog flow or rate variables $\{$ unit $\}$} \\
\hline \multicolumn{2}{|l|}{ Identical with Eq. 24 on Table A1 } \\
\hline \multicolumn{2}{|l|}{ Sector 2.c: Home forecast level (state) or stock variables $\{$ unit\} } \\
\hline \multicolumn{2}{|l|}{ Identical with Eqs 25 through 25.1 on Table A1 } \\
\hline \multicolumn{2}{|l|}{ Sector 2.c: Home forecast flow or rate variables $\{$ unit $\}$} \\
\hline \multicolumn{2}{|l|}{ Identical with Eq. 26 on Table A1 } \\
\hline Sector 2.c: Home forecast auxiliary or converter variables and constants $\{$ unit\} & \\
\hline Identical with Eqs 27 through 29 on Table A1 & \\
\hline
\end{tabular}

Table A3. The home $(H)$ supply-chain model sector equations, under the utS stock policy

\begin{tabular}{lc}
\hline Sector 4: FSAR stock level (state) or stock variables $\{$ unit & Eq. \# \\
\hline $\begin{array}{l}\text { Stock Factory } \Delta(\mathrm{t})=\text { Stock Factory } \Delta(\mathrm{t}-\mathrm{dt})+(\mathrm{add} \Delta) * \mathrm{dt} \\
\text { INIT Stock Factory } \Delta=0\{\mathrm{SKU}\}\end{array}$ & $(49)$ \\
\hline Sector 4: FSAR flow or rate variables $\{$ unit $\}$ & $(50.1)$ \\
\hline add $\Delta=$ IF (change in Stock Factory $>$ Stock Factory $\Delta$ ) THEN (change in Stock Factory / DT) \\
$\quad$ ELSE $(0)$ SKU/week
\end{tabular}

Table A4. Computing the factory stock amplification ratio (FSAR) 